Trends Microbiol. 2020 October ; 28(10): 832-850. doi:10.1016/j.tim.2020.04.010.

\title{
Immunometabolism during Mycobacterium tuberculosis Infection
}

\author{
Nicole C. Howard ${ }^{1}$, Shabaana A. Khader ${ }^{1,}$ \\ ${ }^{1}$ Department of Molecular Microbiology, Washington University School of Medicine, Saint Louis, \\ MO 63110, USA
}

\begin{abstract}
Over a quarter of the world's population is infected with Mycobacterium tuberculosis (Mtb), the causative agent of tuberculosis (TB). Approximately $3.4 \%$ of new and $18 \%$ of recurrent cases of TB are multidrug-resistant (MDR) or rifampicin-resistant. Recent evidence has shown that certain drug-resistant strains of $M t b$ modulate host metabolic reprogramming, and therefore immune responses, during infection. However, it remains unclear how widespread these mechanisms are among circulating MDR $M t b$ strains and what impact drug-resistance-conferring mutations have on immunometabolism during TB. While few studies have directly addressed metabolic reprogramming in the context of drug-resistant $M t b$ infection, previous literature examining how drug-resistance mutations alter $M t b$ physiology and differences in the immune response to drugresistant $M t b$ provides significant insights into how drug-resistant strains of $M t b$ differentially impact immunometabolism.
\end{abstract}

\section{Introduction}

Over a quarter of the world's population is infected with $M t b$, the causative agent of TB. The increasing emergence of drug-resistant strains of $M t b$ significantly limits our efforts to reduce the global TB burden [1]. TB is primarily a pulmonary disease, although disseminated disease can occur [2].The outcome of infection is likely determined by the first interactions between $M t b$ and lung immune cells. After entry into the host's airway, $M t b$ initially infects [3-5] alveolar macrophages (AMs) and subsequently infects recruited interstitial macrophages [6]. However, $M t b$ is also able to reside and thrive in a number of other cellular niches, including dendritic cells (DCs), neutrophils, and non-myeloid cells such as respiratory epithelial cells, fibroblasts, lymphatic endothelial cells, adipocytes, and hematopoietic stem cells [7,8]. Mtb may also be able to persist within extracellular niches, although the duration of extracellular persistence is unclear during pathogenesis [9]. Mtb interaction with the host cells it encounters can be crucially important for determining the outcome of disease progression [10].

After phagocytosis of $M t b$, macrophages initiate a signaling cascade to recruit other immune cells to the lung. This aggregate of immune cells surrounds the site of infection and forms the tubercle granuloma. Mtb utilizes a variety of strategies to avoid or inhibit mechanisms of

\footnotetext{
“Correspondence: sakhader@wustl.edu (S.A. Khader).
} 
host defense in order to survive and replicate within the macrophage and manipulate the cytokine response to infection. The balance of $M t b$ and macrophage interactions can influence the outcome of the granuloma, which may either constrain the infection or promote its systemic dissemination [11,12]. When a macrophage is infected by $M t b$ it can trigger different transcriptional programs that determine how the macrophage responds. Depending on the stimuli they are exposed to, macrophages polarize into either classically activated 'M1' or alternatively activated 'M2' macrophages, or on the spectrum in between these two activation states $[13,14]$. Macrophage polarization is driven by metabolic reprogramming. M1 macrophages are characterized by reliance on glycolysis for energy production, which rapidly generates energy and the accumulation of metabolic intermediates required for the production of proinflammatory cytokines, reactive oxygen species (ROS), nitric oxide (NO), and prostaglandin. By contrast, M2 macrophages commit to utilizing oxidative phosphorylation (OXPHOS) and fatty acid oxidation (FAO), and produce antiinflammatory cytokines such as interleukin (IL)-10 [15].

The pathogenicity of $M t b$ may thus depend on its ability to modulate host metabolism. During $M t b$ infection, the metabolic phenotype of the macrophage can be modulated by the infecting strain of $M t b$ [16], macrophage ontogeny [6], as well as the proximity of other activated immune cells [17]. The macrophage response to $M t b$ likely occurs in waves, beginning with the tissue-resident AMs which are among the first cells to be infected [3-6], followed by lung interstitial monocyte-derived macrophages, which start to accumulate around 2 weeks postinfection [6]. In recent years, our understanding of how Mtb infection drives metabolic reprogramming of these different types of macrophage, and the consequences this has for disease outcome, has expanded.

Most of our knowledge thus far comes from studies using drug-susceptible strains of Mtb. However, although it is recognized that $M t b$ strains of different lineages may drive distinct macrophage metabolic reprogramming, there remains a large gap in our understanding of how drug resistance can impact the host response. Recently, it is becoming clear that drugresistance mutations in $M t b$ can modulate host-pathogen interactions and drive differential metabolic reprogramming [18]. Thus, in this review, we summarize previous literature on how Mtb infection modulates host macrophage metabolism and examine how drugresistance mutations may alter the ability of $M t b$ to drive metabolic reprogramming and survive in host cells.

\section{Macrophage Activation and Metabolism}

Macrophage activation requires shifts in energy metabolism to accommodate the needs of the cell as it responds to pathogens or inflammatory stimuli. Immune cells typically utilize OXPHOS as their primary energy source when quiescent, but stimulation from Toll-like receptors (TLRs) or proinflammatory cytokines can induce metabolic reprogramming to support activation and downstream effector functions [19,20]. Depending on the inflammatory/infection stimulus they receive, macrophages may polarize towards a classically activated proinflammatory M1 phenotype, an alternatively activated immunomodulatory M2 phenotype, or somewhere in between [15,21]. During Mtb infection, recruited monocyte-derived macrophages often express an M1-like phenotype by switching 
to aerobic glycolysis for energy production [22]. This dependence on glycolysis for energy is similar to what is termed the 'Warburg effect' in tumor cells - the utilization of glycolysis and production of lactate while in the presence of oxygen [23]. The central regulator of aerobic glycolysis is hypoxia-inducible factor $1 a$ (HIF-1a), a transcription factor regulating the expression of many glycolytic enzymes [23-25]. TLR activation or signaling by inflammatory mediators, including IL-1 $\beta$ [26], tumor necrosis factor (TNF)- $a[27,28]$, and NO $[29,30]$, induces nuclear factor kappa B (NF-kB) signaling, which then upregulates the expression of HIF-1a [23,31]. In macrophages, the upregulation of HIF-1a expression after Mtb infection is TLR2-dependent, and is mediated in part by the activation of the protein kinase B (AKT)-mechanistic target of the rapamycin (mTOR) pathway [32]. In quiescent or M2 macrophages, the end product of glycolysis, pyruvate, is converted into acetyl coenzyme A (CoA) in the mitochondria and enters the tricarboxylic acid (TCA) cycle [33]. During aerobic glycolysis, however, pyruvate can instead be converted into lactate and secreted from the cell $[24,34,35]$. Lack of the substrate acetyl-CoA, as well as the downregulation of critical TCA cycle and OXPHOS enzymes during $M t b$ infection, further drives the commitment to glycolysis while also allowing immunomodulatory TCA cycle intermediates such as succinate and citrate to accumulate [36].

Macrophage polarization has been suggested to drive the outcome of TB disease in the nonhuman primate (NHP) model. Having a high proportion of alternatively activated macrophages is associated with enhanced bacterial growth and loss of granuloma control in this model [37]. Thus, glycolytically active M1 macrophages are thought to be more effective at controlling $M t b$ infection [6,22] as they are able to rapidly, if inefficiently, produce ATP as well as metabolic intermediates that support the production of proinflammatory cytokines and antimicrobial peptides [38].

\section{Glycolysis}

To support increased rates of glycolysis, macrophages require greater import of glucose into the cell. Activation by inflammatory cytokines or various TLRs, including TLR2, stimulates the upregulation of glucose transporters. Glucose transporters are highly upregulated in macrophages infected with $M t b[39,40]$. Glucose transporter (GLUT)6 is upregulated in murine bone marrow-derived macrophages (BMDMs) infected with $M t b$ [39], while GLUT1 and GLUT3 are upregulated following $M t b$ infection in the human monocytic cell line THP-1 cells or primary human monocyte-derived macrophages (MDMs) [40]. ESAT-6, the 6 $\mathrm{kDa}$ early secretory antigenic target protein of $M t b$, has been shown to mediate increased glucose uptake in THP-1 cells, although the exact mechanism of action is unclear [41]. There is some evidence that ESAT-6 also interacts with TLR2 [42-45], which could be related to its role in stimulating increased glycolysis. However, ESAT-6 has also been implicated in other critical aspects of pathogenesis that may influence the metabolic state of the macrophage, including Mtb escape into the cytosol [46-48]. Therefore, Mtb infection drives increased glucose transport into macrophages through upregulation of glucose transporters (Figure 1). (See Tables 1 and 2.)

However, there may be a decoupling of glucose uptake and glycolysis during Mtb infection. The upregulation of the enzyme 6-phosphofructo-2-kinase/fructose-2,6-biphosphatase 3 
encoded by the gene $P f k f b 3$ is critical for the accumulation of fructose-2,6-biphosphtase (F-2,6-BP) and maintaining glycolytic flux. Expression of $P f k f b 3$ can be differentially regulated by infection with different $M t b$ strains in murine BMDMs, although GLUT6 is upregulated by all strains [36] (Figure 1). This suggests that some Mtb strains do not allow macrophages to fully induce the Warburg effect, which coincides with low induction of proinflammatory responses. This may also be indicative of dysregulated host lipid metabolism, and may represent the induction of an improper immune response that allows for continued Mtb replication [16].

Long-term metabolic changes and epigenetic modifications in innate immune cells represent a process called 'trained immunity'. Blockade of glucose and/or glutamine metabolism in innate cells has been shown to inhibit their ability to undergo this process after BCG vaccination. The establishment of trained immunity after BCG vaccination is reminiscent of the metabolic shift seen during virulent $M t b$ infection, requiring the classical Warburg effect and activation of the AKT-mTOR pathway to undergo epigenetic changes. The establishment of trained immunity in innate cells like monocytes and macrophages has been shown to increase their responsiveness upon later challenge with different pathogens [33]. This shift could impact the ability of $M t b$ to further modulate the metabolic state of host innate immune cells.

Recent work has tracked the metabolic state of macrophages over several days postinfection in murine BMDMs, and has suggested that cellular metabolism is biphasic, with an initial glycolytic proinflammatory stage, followed by a resolution phase characterized by an upregulation of OXPHOS and downregulation of glycolysis. The resolution phase, while allowing for cellular survival, also fails to inhibit bacterial replication as effectively [49]. This may be specific to murine BMDMs as the same was not seen in THP-1 cells or human MDMs after $M t b$ infection. In human macrophages, there is some evidence that $M t b$ may decelerate both glycolysis and OXPHOS [50]. Others have found that. in THP-1 cells, the upregulation of glycolysis after Mtb infection was maintained until $48 \mathrm{~h}$ postinfection (hpi). Treatment of $M t b$-infected THP-1 cells with chemical inhibitors of glycolysis like 2-deoxyD-glucose (2-DG) instead led to a decline in ATP production and subsequent apoptosis once the cell's energy was depleted [40]. Apoptosis is thought to be an important mechanism of host defense; macrophage apoptosis has been found to decrease the viability of Mtb [51-53], and proapoptotic $M t b$ mutants drive greater T cell responses and enhanced host control [54]. This could suggest that while glycolysis is important for driving M1 polarization and an inflammatory macrophage response, the continued survival of the macrophage also provides a niche for $M t b$ growth.

In murine BMDMs, where glycolysis is transiently induced, the critical glycolysis transcription factor HIF-1a is also only upregulated for a short time after Mtb infection, peaking 4 hpi (Figure 1). Expression of HIF-1a was not required for control of bacterial replication during an in vitro infection model [55]. This is surprising, since the inhibition of glycolysis by 2-DG in murine BMDMs [6], THP-1s, or human MDMs impairs the ability of macrophages to control Mtb infection, as shown by increased intracellular bacterial colonyforming units (CFU) [22]. The induction of glycolytic enzymes and increased glucose consumption in macrophages after $M t b$ infection has been shown to be HIF-1a-dependent 
[25,29,56], suggesting that it would also be required for bacterial control. Additionally, it has been shown that HIF- $1 \mathrm{a}^{\text {fl/ffl }} \mathrm{LysM}^{\text {cre }}$ mice were found to be susceptible to $M t b$ infection. However, HIF-1a was found to be required in macrophages for control of $M t b$ infection in the context of interferon (IFN)- $\gamma$ stimulation. IFN- $\gamma$ is a critical mediator of antimycobacterial immunity, and IFN- $\gamma$ stimulation of macrophages has been shown to stimulate metabolic reprogramming [57], as the addition of exogenous IFN- $\gamma$ induces sustained and robust expression of HIF-1a [55]. This does not fully explain the discordant results for the role of HIF-1a, and it bears further study (Figure 1).

The transcription factors NF- $\mathrm{kB}$ and HIF-1a undergo extensive crosstalk in immune cells such as macrophages [58,59]. In $I k k^{-1}$ BMDMs, which cannot activate NF- $\mathrm{BB}, \mathrm{HIF}-1 \mathrm{a}$ protein failed to accumulate and HIF-1a target genes were not expressed after infection with Gram-negative or Gram-positive bacteria [31]. This suggests that NF- $\kappa B$ is required for HIF-1a expression and stabilization during macrophage infection. NF- $\mathrm{\kappa B}$ can canonically be induced in macrophages by various stimuli signaling through cytokine receptors, patternrecognition receptors (PRRs) [60], and TNF superfamily receptors [61] during Mtb infection. NF- $\mathrm{KB}$ is further regulated by various factors associated with modulating the metabolic state of the cell. One particularly important mediator is NO, which is known to be critical for controlling Mtb infection through its bactericidal activity [62-64]. NO is also required for HIF-1a stabilization during IFN- $\gamma$ stimulation, and $\mathrm{Nos}^{-{ }^{--}}$macrophages fail to upregulate GLUT1 or Pfkfb3 to the same extent as wild-type macrophages [29]. NO also suppresses NF- $\kappa \mathrm{B}$ activity, preventing a hyperinflammatory response to $M t b$ infection [29]. In addition to upregulating HIF-1a to enhance the rate of glycolysis, NO also helps to shift macrophage metabolism by inhibiting mitochondrial respiration [65]. Interestingly, a correlation has been found between reduced NO susceptibility and drug resistance in Mtb [66]. Additionally, the anti-inflammatory cytokine IL-10 serves as another layer of regulation of glycolytic commitment by inhibiting $\mathrm{NO}$ and thus mediating the level of OXPHOS suppression in the macrophage [67].

NF- $\mathrm{kB}$ signaling is also regulated by sirtuins (SIRT), important molecules that bridge inflammation and metabolism [68]. SIRT1 is a major metabolic regulator that deacetylates $\mathrm{NF}-\kappa \mathrm{B}$ to promote an anti-inflammatory phenotype and mitochondrial biogenesis. SIRT1 expression is downregulated during $M t b$ infection in macrophages, which may contribute to increased levels of NF- $\kappa \mathrm{B}$ signaling that are important for establishing a proinflammatory, glycolytically active M1 phenotype. Enhancing SIRT1 expression in THP-1 cells has been shown to improve control of $M t b$ growth [69]. In murine peritoneal macrophages and peripheral blood mononuclear cells (PBMCs) taken from human TB patients, SIRT1 was found to be downregulated in a TLR2-dependent manner. It also functioned as a negative regulator of proinflammatory cytokine induction after $M t b$ infection through decreased signaling through the NF- $\mathrm{KB}$ and MAPK pathways [70]. SIRT1 ${ }^{+/-}$mice were more susceptible to $M t b$ infection and developed increased immunopathology, suggesting that SIRT1 has a role in both controlling $M t b$ and preventing tissue destruction. Like SIRT1, SIRT6 is a well-studied regulator of glycolysis and lipid metabolism, but it is upregulated during $M t b$ infection. SIRT6 negatively regulates NF- $\mathrm{kB}$ (Figure 1) and aerobic glycolysis; deletion of SIRT6 in macrophages results in enhanced M1 polarization and increased glucose metabolism [71]. Blockade of SIRT6 results in reduced blood sugar through 
increased GLUT expression and glycolysis. However, it is not known whether SIRT6 plays a protective or pathologic role in $M t b$ infection.

\section{TCA Cycle}

Integration of glycolysis with the TCA cycle is mediated through oxidation of pyruvate to acetyl-CoA. Mtb infection drives the downregulation of several critical TCA cycle enzymes [36] as well as the conversion of pyruvate to lactate [22]. This results in an accumulation of TCA cycle intermediates, particularly the metabolites succinate and citrate, which are important substrates for the generation of immunomodulatory molecules (Figure 2).

Succinate inhibits HIF prolyl hydroxylases to increase HIF-1a stabilization [72], and it also promotes production of the proinflammatory cytokine IL-1 $\beta$ [23], which has been shown to be crucial for controlling $M t b$ infection in macrophages [22,73,74]. Accumulation of succinate relies on the inhibition of succinate dehydrogenase (SDH) activity; this enzyme has been found to be downregulated during $M t b$ infection in macrophages [36]. Succinate oxidation by SDH in the electron transport chain (ETC), and increased membrane potential as a result of glycolysis, can also lead to mitochondrial production of ROS [75].

Mitochondrial ROS is produced by the NADPH-dependent NOX2 oxidase complex, and ROS can kill microbes with a variety of mechanisms. Mice deficient in NADPH oxidase are highly susceptible to $M t b$ infection, and $M t b$ has many different mechanisms of maintaining redox balance in order to survive ROS exposure and oxidative stress [76]. The downregulation of SDH by Mtb may be another such mechanism for avoiding excessive ROS generation. Glutathione (GSH) is an important antioxidant that can help to maintain cellular redox balance. Its synthesis is increased in $M t b$-infected macrophages, as is xCT (SLC7A11) expression, which imports cysteine, the GSH substrate. xCT deficient mice have increased ability to control $M t b$ growth and have reduced pathology [77], suggesting this as another potential mechanism by which $M t b$ survives oxidative stress in host cells.

During virulent $M t b$ infection, there is still increased acetyl coenzyme-A (Ac-CoA) synthesis. However, rather than cycling Ac-CoA through the TCA cycle and utilizing OXPHOS for energy generation, the TCA cycle intermediate citrate is instead exported from the mitochondria to the cytoplasm [40]. Citrate accumulation is likely mediated by downregulation of the enzyme isocitrate dehydrogenase 2 (IDH2) [78], which represents a breakpoint where the metabolite isocitrate can be diverted from the TCA cycle. It is exported from the mitochondria to the cytosol where it is metabolized to Ac-CoA, resulting in a cytoplasmic pool of this important precursor to various inflammatory mediators in macrophages, such as NO, ROS, and prostaglandin $\mathrm{E}_{2}$ (PGE2) [79-81]. Like succinate, citrate also inhibits HIF hydroxylases, thus contributing to HIF-1a stabilization and activity [72].

SDH is also regulated by itaconate, which is generated from citrate by the decarboxylation of cisaconitate by the enzyme aconitate decarboxylase 1 (ACOD1). While itaconate is important for the inhibition of SDH it also plays many other critical roles during $M t b$ infection. It mediates an anti-inflammatory response that prevents excess immunopathology; when $\mathrm{LysM}^{+}$myeloid cells lack ACOD1, they succumb rapidly to $M t b$ infection as a result of neutrophil-mediated inflammation [82]. In macrophages, itaconate suppresses the 
production of ROS as well as proinflammatory cytokines like IL-1 $\beta$, IL-6, and IL-12p70. It also has a role in increasing mitochondrial respiration rates, even after murine BMDMs undergo M1 polarization [83]. Therefore, the downregulation of TCA cycle flux and subsequent accumulation of metabolic intermediates may represent a protective host response to prime macrophages to release ROS and other proinflammatory molecules (Figure 2).

\section{OXPHOS}

The TCA cycle reduces nicotinamide adenine dinucleotide $\left(\mathrm{NAD}^{+}\right)$to $\mathrm{NADH}$, which is then fed into the OXPHOS pathway. During Mtb infection and M1 polarization of macrophages, there is an increased requirement for $\mathrm{NAD}^{+}$and decreased ability of mitochondria to oxidize $\mathrm{NADH}$. $M t b$ also secretes an $\mathrm{NAD}^{+}$glycohydrolase known as tuberculosis necrotizing toxin that contributes further to the depletion of $\mathrm{NAD}^{+}$to potentially trigger necroptosis in infected cells [84]. Macrophages attempt to maintain homeostasis by increasing NAD synthesis. Accordingly, expression of nicotinamide phosphoribosyltransferase (Nampt), the first enzyme in the NAD synthesis pathway, is increased in $M t b$-infected murine macrophages. Nampt is regulated by SIRT6, which is also upregulated by Mtb infection [36]. SIRT6 deacetylates Nampt, resulting in increased activity [85]. SIRT6 may therefore help to maintain balance during $M t b$ infection, preventing an overly inflammatory response and prolonging macrophage survival.

Resting and M2 macrophages are characterized by their reliance on OXPHOS for ATP production. During $M t b$ infection, the enzymes involved in OXPHOS are downregulated [39]. During the early phase of infection, decreased OXPHOS in the mitochondria leads to ROS and reactive nitrogen species (RNS) production. NOS2 is highly upregulated by Mtb has been shown to be critically important for protection in murine macrophages, though its role in human infection is more controversial. RNS also inhibit the ETC and mitochondrial function, leading to reduced redox and increased ROS [86,87] (Figure 2). Elevated oxidative stress may be a mechanism by which $M t b$ drives macrophage necrosis in order to better facilitate bacterial replication [88].

However, oxidative metabolism may be upregulated at later time points during $M t b$ infection of murine BMDMs, as glucose uptake and glycolysis is downregulated and the TCA cycle/ OXPHOS are upregulated after $24 \mathrm{~h}$ postinfection. This switch back to OXPHOS may be regulated by the late induction of a member of the PPAR $\gamma$ coactivator-1 (PGC-1) family, $P g c 1 b$, which is involved in mitochondrial biogenesis. This may represent a resolution phase of infection, meant to avoid immunopathology, while allowing $M t b$ to better survive in the host cell [36]. There is also evidence that, in human monocytes and MDMs, Mtb may decelerate both glycolysis and OXPHOS, leading to increased dependency on FAO for energy generation [50].

\section{Fatty Acid and Lipid Metabolism}

Citrate exported from the mitochondria is cleaved to generate cytoplasmic Ac-CoA, which is subsequently converted to mevalonate (MVA) and malonyl-CoA (Ma-CoA) to support the synthesis of cholesterol or free fatty acids (FAs), respectively [40]. During macrophage 
infection, $M t b$ prevents phagolysosome maturation and escapes into the cytosol, where cholesterol and FAs, contained in lipid droplets, are accessible as a nutrient source [89]. In human MDMs, mycobacteria-containing phagosomes even migrate towards lipid bodies, leading to the incorporation of host lipids in the bacteria [90]. Several models have been described for increased lipid biogenesis in macrophages upon Mtb infection. The mycobacterial surface is enriched in nonpolar lipids, and these lipids are proposed to promote the emergence of neutral lipid-rich macrophages. Alternative models of increased de novo FA synthesis and inhibition of lipolysis mediated by perilipin $1 \mathrm{~A}$ have also been suggested [91]. Necrosis induced by Mtb infection may also facilitate the differentiation of bystander macrophages to foamy macrophages [91]. Host factors also play an important role, including HIF-1a and TNFa. HIF-1a expression has also been shown to decrease the rate of $\beta$-oxidation and increase accumulation of the neutral lipid triacylglycerol (TAG), which supports the formation of lipid droplets during Mtb infection of macrophages [92]. Lipid-laden macrophages can develop into foamy macrophages, which are associated with necrotic granulomas $[90,93]$. The proinflammatory cytokine IL-17 downregulates HIF-1a and negatively regulates the formation of hypoxic, necrotic granulomas in mice, suggesting that HIF-1a contributes to the formation of foamy macrophages [94]. During in vitro infection of human MDMs, MDMs that did not harbor intracellular Mtb still accumulated lipid droplets, but blockade of TNFa or its receptor TNFR inhibited lipid droplet formation in $M t b^{+}$and $M t b^{-}$cells [95]. Inhibition of cholesterol or FA results in reduced lipid body accumulation in macrophages infected with $M t b$, as well as reduced intracellular CFU [40]. This is somewhat controversial, as new evidence suggests that $M t b$ is restricted from acquiring host lipids in IFN- $\boldsymbol{\gamma}$-activated macrophages [96].

Ketone body synthesis is an alternate pathway for utilizing mitochondrial Ac-CoA, particularly when Ac-CoA is produced in greater quantities than can be used in the TCA cycle [97], such as when the TCA cycle is inhibited during $M t b$ infection. During $M t b$ infection, there is increased expression of the ketone body 3HB, an agonist of the GiPCR GPR109a, which reduces cellular cAMP and decreases perilipin phosphorylation to protect lipid bodies from lipolysis [41] and drive lipid droplet formation. Blockade of GPR109a has been shown to effectively lower Mtb CFU in vivo, evenduring MDR Mtb infections [41], suggesting that DS and DR Mtb strains need lipid bodies as a nutrient source (Figure 2).

The increased synthesis and turnover of long-chain fatty acyl-CoAs can also increase PGE production, a lipid mediator important for controlling Mtb infection. However, lipid metabolism can be manipulated by the infecting $M t b$ strain, with different strains inducing different patterns of gene expression. The hypervirulent lineage 2 Mtb strain HN878 drives fatty acid synthase (FASN) expression, while other $M t b$ strains, like the laboratory-adapted H37Rv, do not [16,98] (Figure 2). While FASN does drive the expression of proinflammatory cytokines, like IL- $1 \beta$ and TNFa, and contributes to macrophage activation, it also drives the synthesis of cholesterol [99], which is an important nutrient source for $M t b$ [100]. Mycolic acids have also been found to have a role in the accumulation of cholesterol inside alveolar macrophages, which may therefore contribute to foam cell formation. MAs are a major type of lipid in the mycobacterial cell wall, and are critical for maintaining the structure of the wall [101]. 
HN878 also generates more Acyl-CoA synthetase long-chain family member 4 (Acs14), which favors arachidonate and eicosapentaenoate production [16,102], while the lineage 4 strain CDC1551 induces expression of the calcium-sensitive cytosolic phospholipase A2 (cPla2), which results in amino acid (AA) liberation from cellular phospholipids. Expression of cPla2 also generates increased PGE2 induction during CDC1551 infection [16,53]. Mtbinduced apoptosis relies on cPla2 [103] through PGE2 and other lipid mediators and subsequently the cyclooxygenases COX1 and 2 [104]. PGE2 is balanced by lipoxins such as lipoxin A4 (LXA4), which have anti-inflammatory effects [105] (Figure 2). Modulating the balance between these two eicosanoids may be a potential mechanism by which $M t b$ skews the macrophage towards necrosis or apoptosis. PGE2 suppresses necrosis, while LXA4 promotes it [53].

Together, these studies demonstrate that metabolic regulation of host cells, particularly macrophages, is a critical component of both host defense and pathogenesis during drugsusceptible $M t b$ infection. Host macrophages have highly coordinated programs of inflammatory responses established through metabolic reprogramming following infection, which primes them to effectively control invading pathogens. However, Mtb may be able to perturb cellular metabolism in order to modulate the immune response and establish its own survival and persistence. Although our understanding of immunometabolism during $M t b$ infection has greatly increased in recent years, recent evidence suggests that MDR Mtb strains differentially regulate these responses [18] and require further study.

\section{MDR TB}

The role that drug resistance may play in altering $M t b$ physiology, and subsequently altering its interactions with host cells, has been highly understudied. There is a growing body of evidence that, despite highly conserved genomes between $M t b$ strains [106], the genetic background of the $M t b$ strain can still induce differential responses during infection [5,94,107-110], and some of this has been linked back to differences in the cell-wall composition between these strains $[94,111,112]$. The cell wall of $M t b$ is critically important for modulating the immune response of the host, and changes in $M t b$ cell wall lipid composition can drastically change the immune response during infection. Many drugresistance mutations in $M t b$ are associated with perturbations in the cell wall lipid composition [113,114], and particularly in the case of rifampicin-resistance-conferring $r p o B$ mutations, cell-wall biosynthesis and cellular metabolism pathways may be heavily impacted [18,115]. Recent evidence suggests that $r p o B$ SNPs may mediate differential induction of host immune responses during infection, as a consequence of changes in cellwall-associated lipid expression [18]. Thus, drug resistance mutations could potentially change the environment that $M t b$ must survive in in the macrophage, while also altering the bacilli's ability to respond to and process the nutrients available in this niche. The impact this has on disease pathogenesis is unclear. Thus, there is a critical need to better understand the physiology and pathogenesis of drug-resistant strains of $M t b$ and interactions with its host in order to develop novel effective therapeutic options.

In particular, very little has been done to directly investigate macrophage metabolic reprogramming after drug-resistant (DR) or MDR Mtb infection. In order to bridge this gap, 
it may be possible to link the literature examining how drug-resistance mutations alter $M t b$ physiology with the known differences in the immune response to DR $M t b$, and provide insights into how drug-resistant strains of $M t b$ drive metabolic reprogramming during infection.

\section{Glycolysis}

One of the initial steps in mediating macrophage reprogramming is TLR stimulation, especially TLR2, which is required to drive the upregulation of HIF-1a and commit the macrophage to aerobic glycolysis. Interestingly, there is some indication that drug resistance in $M t b$ may mediate how much TLR2 is stimulated during infection. When assessing an extensively drug-resistant (XDR) and DS $M t b$ strain of the same family, it was found that the XDR $M t b$ stimulated TLR2 to a lower extent than the DS $M t b$ in THP-1 cells, leading to reduced induction of both pro- and anti-inflammatory cytokines, which suggests an altered metabolic state of the macrophage [116]. MDR TB patients have an altered ratio of IFN- $\gamma /$ IL-10 in serum in comparison with DS TB patients, with MDR TB patients having high levels of IL-10 and lower levels of IFN- $\gamma[117,118]$. Like TLR2 stimulation, IFN- $\gamma$ is critical for the sustained upregulation of HIF-1a. However, ESAT-6, which has also been implicated in increased glucose uptake to support aerobic glycolysis, has been shown to be upregulated in particular MDR Mtb isolates [119], suggesting that MDR Mtb strains may strongly induce glucose uptake during macrophage infection. Thus, DR Mtb may have increased expression of ESAT- 6 but decreased TLR2 stimulation and IFN- $\gamma$ signaling, making it unclear if the infected macrophages are able to commit to aerobic glycolysis to support M1 polarization after infection (Figure 3).

TLR2 signaling is also required for expression of the inflammatory eicosanoid PGE2 [120], while immunoregulatory signals, like type I IFN and IL-10, both downregulate PGE2 expression through their inhibition of IL-1 signaling [121]. Both type I IFN [18] and IL-10 $[117,118]$ signaling is increased during MDR Mtb infection, while TLR2 signaling is decreased [116], which would suggest that PGE2 is likely downregulated. However, this has not been demonstrated during MDR Mtb infection. It has been suggested that MDR TB results in increased pulmonary cavitation in patients [122,123], a process thought to be induced through necrosis [49], but there may be many mechanisms driving that response.

Like PGE2, SIRT6 is strongly regulated by the type I IFN response [124]. The role of SIRT6 during $M t b$ infection is not entirely understood, although it is known to be upregulated by DS $M t b$ infection in macrophages, and negatively regulates NF- $\mathrm{kB}$ signaling, glucose metabolism, and M1 polarization [71]. As some DR Mtb strains more strongly induce type I IFN [18], it is possible that they also more strongly induce SIRT6. The role type I IFNs play during DR $M t b$ infection is still unclear, but they may in fact be beneficial for the host; type I IFN administration has been beneficial in the treatment of MDR TB patients [125,126].

Chemical inhibition of glycolysis after $M t b$ infection exacerbates disease and raises intracellular CFU in macrophages, suggesting that glycolysis is necessary for macrophage activation. It has been hypothesized that this could be due to defective induction of IL-1 $\beta$, which is known to be critical for controlling $M t b$. Macrophages treated with the inhibitor 2DG were unable to produce IL- $1 \beta$ and, as a result, were unable to control bacterial 
replication as treatment of $I 11 r 1^{-1-}$ macrophages with 2-DG had no effect, suggesting that glycolysis was upstream of IL-1 signaling [22]. Human macrophages infected with MDR $M t b$ from various lineages produced variable amounts of IL- $1 \beta$ in comparison with $\mathrm{H} 37 \mathrm{Rv}$ infection [127], which could suggest that drug resistance is modulating the metabolic state of the cell, or inhibiting expression at a different stage. While differential IL-1 $\beta$ induction in murine BMDMs has also been shown for some rifampicin-resistant $M t b$ strains in comparison with DS Mtb of the same background, the strains used by Chakraborty et al. [127] were from multiple lineages. Therefore, differences in IL-1 $\beta$ production could likely be lineage-dependent rather than their drug resistance profiles (Figure 3).

During aerobic glycolysis, pyruvate can be converted into lactate rather than entering the TCA cycle as Ac-CoA. Mtb has also recently been shown to metabolize lactate as a carbon source. Mutants that lack the L-lactate dehydrogenase gene $1 l d D 2$ are unable to utilize lactate and have impaired replication in human macrophages [128]. Interestingly, IIdD2 expression has been found to be significantly upregulated in isoniazid (INH)-resistant $M t b$ strains in comparison with closely related DS strains [129] (Figure 3), which may affect their growth in glycolytically active cells during infection.

\section{OXPHOS}

While there is limited direct evidence that DR strains of $M t b$ also shut down OXPHOS to a similar extent as DS Mtb strains [18], MDR and XDR Mtb strains have been found to induce high levels of oxidative stress in macrophages, even in bystander uninfected cells, when compared with H37Rv [130], which suggests that OXPHOS is likely being downregulated (Figure 3). While the MDR and XDR strains were not of the same lineage as H37Rv, they were from four distinct lineages and consistently produced similar results in comparison with H37Rv, suggesting that it is unlikely to be a lineage-dependent effect. Interestingly, DR $M t b$ strains may also be more resistant to ROS than drug-susceptible strains. Mutations in the gene encoding alkyl hydroperoxide reductase subunit $\mathrm{C}(\operatorname{ahp} C)$ frequently occur to compensate for the loss of fitness associated with INH resistance [131]. However, they are also associated with resistance to ROS [132], which may contribute to why DR Mtb strains have some resistance to RNS stress as well. A correlation has also been found between reduced NO susceptibility and drug resistance in $M t b[66]$. However, it is not known if this is related to the direct antimicrobial effects of RNS or if it indicates an improved ability of drug-resistant $M t b$ to reside in M1 glycolytically active macrophages. Additionally, IL-10 serves as another layer of regulation of glycolytic commitment by inhibiting NO and thus mediating the level of OXPHOS suppression in the macrophage [67]. Given the enhanced levels of IL-10 in the inflammatory milieu of MDR TB [117,118], it is possible that MDR $M t b$ strains drive M2-like rather than M1 polarization of macrophages through this mechanism. Accordingly, the M2-like polarization rate of macrophages is significantly higher in granulomas from resected lungs of MDR/XDR TB patients, when compared with granulomas from DS TB patients, although there was no difference in the M1-like polarization rate between the groups [133]. M1 and M2 polarization states were defined by the expression of iNOS and arginase-1 surface markers respectively. However, as these results were generated from patients with severely progressed disease, they may not be broadly representative, and thus these results should be confirmed in other TB disease 
models and Mtb strains. Within many of these human studies it also remains unclear if differences in the lineage background or growth rate of DR isolates, compared with DS isolates, could be confounding factors in the study results.

\section{FA Oxidation}

FA and cholesterol are nutrients available to intracellular $M t b$ that are important for $M t b$ survival and virulence, but their degradation generates propionyl-CoA, a byproduct toxic to the bacteria. Therefore, $M t b$ has multiple mechanisms for removing propionyl-CoA, including incorporating it into methyl-branched lipids in the cell wall. The proteins PDIM, SL-1, PAT, and LOS are commonly used as a sink for propionyl-CoA [134]. This is particularly interesting in the context of drug resistance since it has been shown by multiple groups that $r p o B$ mutations can induce up-regulation of some of these methyl-branched lipids $[18,113,135]$ - which may better allow DR $M t b$ to reside in host macrophages and mitigate stress. Conversely, failing to induce FA accumulation may be especially detrimental to the survival of DR $M t b$ strains as lacking substrates to incorporate into methyl-branched lipids may cause additional stress due to nutrients being inappropriately allocated during infection.

The observed increase in central metabolism may affect the fitness of drug-resistant strains during infection. In INH-resistant clinical and laboratory-generated strains, there was an increased abundance of enzymes in the TCA cycle, including IldI2. Additionally, there was an increased abundance of genes involved in FA $\beta$-oxidation, which together may suggest increased ATP production. Unlike $r p o B$ mutants, there was not an increase in methylbranched lipids in the cell wall, suggesting that different drug-resistance mutations differentially influence $M t b$ physiology how it reacts to the macrophage environment [136]. These findings also highlight one of the challenges of understanding MDR Mtb, when drugresistance-conferring mutations may induce opposing effects.

Mycolic acids, which contribute to triggering foam-cell formation, have been found at an increased abundance in some DR $M t b$ strains in comparison with DS $M t b$ strains [137] (Figure 3). This suggests that some DR Mtb strains may have an enhanced ability to accumulate FA nutrient sources in macrophages through the increased development of lipid bodies. Other DR $M t b$ strains, particularly mono-INH-resistant isolates, have been found to have lower levels of mycolic acids in their cell walls, as well as a downregulation of the enzymes involved in their synthesis. However, these strains are also associated with lower virulence and survival during in vivo infection in comparison with closely related DS Mtb strains [136,138], with no notable differences during growth in media, perhaps in part because of this defect or other underlying fitness defects.

TAG accumulation in human macrophages also requires TNF- $a$ signaling after $M t b$ infection [95]. TNF-a signaling is closely linked to IL-1R signaling, which upregulates TNFR expression [139], and IL-1 signaling is perturbed by certain MDR Mtb strains [18]. It is unclear how TNF-a cytokine expression is affected, as some DR TB patients have lower expression [140] and others have enhanced expression in the serum in comparison with DS TB patients [117], which suggests that some DR strains may differentially accumulate TAG if TNF signaling is modulated. Infection of MDMs isolated from MDR TB patients by an 
MDR $M t b$ strain strongly induced TNF-a production, significantly more so than infection of MDMs isolated from DS TB patients or healthy controls. This correlated with increased bacterial CFU in the MDR TB patients MDMs [141], suggesting that enhanced TNF-a expression was playing a pathogenic role, perhaps through lipid accumulation and foam cell biogenesis.

\section{Metabolic Drugs/Therapies}

TAG and neutral lipid accumulation leads to necrosis and facilitates escape of bacilli from host cells to spread infection. Thus, extracellular glucose concentrations influence the balance between apoptosis and necrosis, and consequently $M t b$ spread. Models that modulate the availability of extracellular glucose therefore impact $M t b$ pathogenesis. Diabetes models, where glucose levels are high, result in increased Mtb CFU. However, in a hypoglycemia model, the opposite result was found where macrophages were better able to control Mtb infection [40]. Type 2 diabetes has been found to be associated with increased likelihood of DR Mtb infection [142-144]. Additionally, diabetes is associated with an increased risk of both treatment failure and death during MDR TB disease [145]. T2D alters macrophage activation and their ability to respond to $M t b$ infection [146]. In particular, IL-1 $\beta$ and IL-10 secretion was altered in the T2D macrophages, and those pathways are known to be modulated by DR Mtb infection in comparison with DS Mtbinfection as well. Enhanced oxidative stress may also have an impact on comorbidities like diabetes, as increased oxidative stress may result in poor treatment outcomes [147]. The antidiabetic drug metformin (MET) reduces the intracellular growth of $M t b$ in an AMPK (adenosine monophosphate-activated protein kinase)-dependent manner. MET is typically prescribed to aid in lowering excess levels of blood glucose. In the context of $M t b$ it was found to increase the production of mitochondrial ROS and facilitate phagolysosome fusion to control the growth of DS and DR Mtb strains [148]. Unfortunately, a retrospective cohort study showed that MET treatment failed to significantly improve TB control in TB patients who also had diabetes. While some patients also had DR TB, they were not analyzed separately [149].

\section{Concluding Remarks and Future Perspectives}

Our understanding of how host macrophage metabolism can influence the outcome of $M t b$ infection has grown considerably over the past years. While it is increasingly clear that appropriate metabolic activation of macrophages is critical for controlling Mtb infection, it remains understudied how drug-resistant $M t b$ strains may modulate the paradigms being uncovered. In particular, drug-resistance mutations in $M t b$ seem to mediate changes in cellwall biosynthesis and bacterial metabolism, which suggests that DR Mtb modulates the host response to infection in two ways: (i) by altering the expression of lipids and proteins that are sensed by host cells, and (ii) by altering their own need for nutrients or a host environment. These changes could be detrimental or beneficial to pathogenesis, but an enormous amount of work remains to fully understand the effect of drug-resistance mutations on bacterial physiology, both singly and in combination, and then to examine their subsequent role in mediating an immune response. Based on the literature reviewed here, it is likely that many of the currently circulating MDR Mtb strains modulate host immune 
responses, driven by changes in immunometabolism. Future studies are needed to elucidate the relationship between drug resistance in $M t b$ and host metabolism during infection.

\section{Acknowledgments}

This work was supported by Washington University in St Louis, National Institutes of Health (NIH) grants R01 HL105427, R01 AI134236, R01 AI111914, R01 AI123780 to S.A.K, and N.C.H. was supported on NIH Training grant T32 HL007317-41.

\section{References}

1. WHO (2018) Global Tuberculosis Report 2018, World Health Organization

2. Norbis L et al. (2014) Challenges and perspectives in the diagnosis of extrapulmonary tuberculosis. Exp. Rev. Anti. Infect. Ther 12, 633-647

3. Rothchild AC et al. (2019) Alveolar macrophages generate a noncanonical NRF2-driven transcriptional response to Mycobacterium tuberculosis in vivo. Sci. Immunol 4, eaaw6693 [PubMed: 31350281]

4. Cohen SB et al. (2018) Alveolar macrophages provide an early Mycobacterium tuberculosis niche and initiate dissemination. Cell Host Microbe 24, 439-446.e4 [PubMed: 30146391]

5. Dunlap MD et al. (2018) A novel role for C-C motif chemokine receptor 2 during infection with hypervirulent Mycobacterium tuberculosis. Mucosal Immunol. 11, 1727-1742 [PubMed: 30115997]

6. Huang L et al. (2018) Growth of Mycobacterium tuberculosis in vivo segregates with host macrophage metabolism and ontogeny. J. Exp. Med 215, 1135 [PubMed: 29500179]

7. Bussi C and Gutierrez MG (2019) Mycobacterium tuberculosis infection of host cells in space and time. FEMS Microbiol. Rev 43, 341-361 [PubMed: 30916769]

8. Mayito J et al. (2019) Anatomic and cellular niches for Mycobacterium tuberculosis in latent tuberculosis infection. J. Infect. Dis 219, 685-694 [PubMed: 30376080]

9. Hirayama Y et al. (2009) Mycobacteria exploit host hyaluronan for efficient extracellular replication. PLoS Pathog. 5, e1000643 [PubMed: 19876387]

10. McNicholl JM et al. (2000) Host-pathogen interactions in emerging and re-emerging infectious diseases: a genomic perspective of tuberculosis, malaria, human immunodeficiency virus infection, hepatitis B, and cholera. Annu. Rev. Public Health 21, 15-46 [PubMed: 10884944]

11. Ulrichs T and Kaufmann SHE (2006) New insights into the function of granulomas in human tuberculosis. J. Pathol 208, 261-269 [PubMed: 16362982]

12. Davis JM and Ramakrishnan L (2009) The role of the granuloma in expansion and dissemination of early tuberculous infection. Cell 136, 37-49 [PubMed: 19135887]

13. Xue J et al. (2014) Transcriptome-based network analysis reveals a spectrum model of human macrophage activation. Immunity 40, 274-288 [PubMed: 24530056]

14. Murray PJ et al. (2014) Macrophage activation and polarization: nomenclature and experimental guidelines. Immunity 41, 14-20 [PubMed: 25035950]

15. O’Neill LA and Pearce EJ (2016) Immunometabolism governs dendritic cell and macrophage function. J. Exp.Med 213, 15-23 [PubMed: 26694970]

16. Koo M-S et al. (2012) Strain specific transcriptional response in Mycobacterium tuberculosis infected macrophages. Cell Commun. Signal 10, 2-2 [PubMed: 22280836]

17. Bénard A et al. (2018) B Cells producing type I IFN modulate macrophage polarization in tuberculosis. Am. J. Respir. Crit.Care Med 197, 801-813 [PubMed: 29161093]

18. Howard NC et al. (2018) Mycobacterium tuberculosis carry ing a rifampicin drug resistance mutation reprograms macro phage metabolism through cell wall lipid changes. Nat.Microbiol 3, 1099-1108 [PubMed: 30224802]

19. Rodríguez-Prados J-C et al. (2010) Substrate fate in acti vated macrophages: a comparison between innate, classic, and alternative activation. J. Immunol 185, 605 [PubMed: 20498354] 
20. Kelly B and O’Neill LAJ (2015) Metabolic reprogramming in macrophages and dendritic cells in innate immunity. Cell Res. 25, 771-784 [PubMed: 26045163]

21. Russell DG et al. (2019) Immunometabolism at the interface between macrophages and pathogens. Nat. Rev. Immunol 19, 291-304 [PubMed: 30679807]

22. Gleeson LE et al. (2016) Cutting edge: Mycobacterium tuberculosis induces aerobic glycolysis in human alveolar macrophages that is required for control of intracellular bacillary replication. J. Immunol 196, 2444-2449 [PubMed: 26873991]

23. Tannahill GM et al. (2013) Succinate is an inflammatory signal that induces IL-1 $\beta$ through HIF-1a. Nature 496, 238-242 [PubMed: 23535595]

24. Semenza GL et al. (1994) Transcriptional regulation of genes encoding glycolytic enzymes by hypoxia-inducible factor 1. J. Biol. Chem 269, 23757-23763 [PubMed: 8089148]

25. Cramer T et al. (2003) HIF-1alpha is essential for myeloid cell-mediated inflammation. Cell 112, 645-657 [PubMed: 12628185]

26. Jung Y-J et al. (2003) IL-1 $\beta$-mediated up-regulation of HIF-1a via an NFkB/COX-2 pathway identifies HIF-1 as a critical link between inflammation and oncogenesis. FASEB J. 17, 21152117 [PubMed: 12958148]

27. Jung Y et al. (2003) Hypoxia-inducible factor induction by tumour necrosis factor in normoxic cells requires receptor-interacting protein-dependent nuclear factor kappa B activation. Biochem. $\mathbf{J}$ 370, 1011-1017 [PubMed: 12479793]

28. Tsapournioti S et al. (2013) TNFa induces expression of HIF-1a mRNA and protein but inhibits hypoxic stimulation of HIF-1 transcriptional activity in airway smooth muscle cells. J. Cell. Physiol 228, 1745-1753 [PubMed: 23359428]

29. Braverman J and Stanley SA (2017) Nitric oxide modulates macrophage responses to Mycobacterium tuberculosis infection through activation of HIF-1a and repression of NF- $\mathrm{kB}$. J. Immunol 199, 1805-1816 [PubMed: 28754681]

30. Mateo J et al. (2003) Regulation of hypoxia-inducible factor-1alpha by nitric oxide through mitochondria-dependent and -independent pathways. Biochem. J 376, 537-544 [PubMed: 14531732]

31. Rius J et al. (2008) NF-kappaB links innate immunity to the hypoxic response through transcriptional regulation of HIF-1alpha. Nature 453, 807-811 [PubMed: 18432192]

32. Lachmandas E et al. (2016) Rewiring cellular metabolism via the AKT/mTOR pathway contributes to host defence against Mycobacterium tuberculosis in human and murine cells. Eur. J. Immunol 46, 2574-2586 [PubMed: 27624090]

33. Arts RJW et al. (2016) Immunometabolic pathways in BCG-induced trained immunity. Cell Rep. 17, 2562-2571 [PubMed: 27926861]

34. Kim J-W et al. (2006) HIF-1-mediated expression of pyruvate dehydrogenase kinase: A metabolic switch required for cellular adaptation to hypoxia. Cell Metab. 3, 177-185 [PubMed: 16517405]

35. Palsson-McDermott EM et al. (2015) Pyruvate kinase M2 regulates Hif-1a activity and IL-1 $\beta$ induction and is a critical determinant of the warburg effect in LPS-activated macrophages. Cell Metab. 21, 65-80 [PubMed: 25565206]

36. Shi L et al. (2019) Biphasic dynamics of macrophage immunometabolism during Mycobacterium tuberculosis infection. mBio 10, e02550-18 [PubMed: 30914513]

37. Marino S et al. (2015) Macrophage polarization drives granuloma outcome during Mycobacterium tuberculosis infection. Infect. Immun 83, 324 [PubMed: 25368116]

38. Nagy C and Haschemi A (2015) Time and demand are two critical dimensions of immunometabolism: the process of macrophage activation and the pentose phosphate pathway. Front. Immunol 6, 164 [PubMed: 25904920]

39. Shi L et al. (2015) Infection with Mycobacterium tuberculosis induces the Warburg effect in mouse lungs. Sci. Rep 5, 18176 [PubMed: 26658723]

40. Mehrotra P et al. (2014) Pathogenicity of Mycobacterium tuberculosis is expressed by regulating metabolic thresholds of the host macrophage. PLoS Pathog. 10, e1004265 [PubMed: 25058590]

41. Singh V et al. (2012) Mycobacterium tuberculosis-driven targeted recalibration of macrophage lipid homeostasis promotes the foamy phenotype. Cell Host Microbe 12, 669-681 [PubMed: 23159056] 
42. Chatterjee S et al. (2011) Early secreted antigen ESAT-6 of Mycobacterium tuberculosis promotes protective T helper 17 cell responses in a toll-like receptor-2-dependent manner. PLoS Pathog. 7, e1002378 [PubMed: 22102818]

43. Liu W et al. (2014) The involvement of NADPH oxidase-mediated ROS in cytokine secretion from macrophages in duced by Mycobacterium tuberculosis ESAT-6. Inflammation 37, 880-892 [PubMed: 24408010]

44. Pathak SK et al. (2007) Direct extracellular interaction be tween the early secreted antigen ESAT-6 of Mycobacterium tuberculosis and TLR2 inhibits TLR signaling in macrophages. Nat. Immunol 8, 610 [PubMed: 17486091]

45. Yang S et al. (2015) Early secreted antigen ESAT-6 of Mycobacterium tuberculosis promotes apoptosis of macrophages via targeting the microRNA155-SOCS1 interaction. Cell. Physiol. Biochem 35, 1276-1288 [PubMed: 25721573]

46. Houben D et al. (2012) ESX-1-mediated translocation to the cytosol controls virulence of mycobacteria. Cell. Microbiol 14, 1287-1298 [PubMed: 22524898]

47. Simeone R et al. (2012) Phagosomal rupture by Mycobacterium tuberculosis results in toxicity and host cell death. PLoS Pathog. 8, e1002507 [PubMed: 22319448]

48. van der Wel N et al. (2007) M. tuberculosis and M. leprae translocate from the phagolysosome to the cytosol in myeloid cells. Cell 129, 1287-1298 [PubMed: 17604718]

49. Dheda K et al. (2019) Spatial network mapping of pulmonary multidrug-resistant tuberculosis cavities using RNA sequencing. Am. J. Respir. Crit. Care Med 200, 370-380 [PubMed: 30694692]

50. Cumming BM et al. (2018) Mycobacterium tuberculosis induces decelerated bioenergetic metabolism in human mac rophages. eLife 7, e39169 [PubMed: 30444490]

51. Divangahi M et al. (2009) Mycobacterium tuberculosis evades macrophage defenses by inhibiting plasma membrane repair. Nat. Immunol 10, 899-906 [PubMed: 19561612]

52. Oddo M et al. (1998) Fas ligand-induced apoptosis of infected human macrophages reduces the viability of intracellular Mycobacterium tuberculosis. J. Immunol 160, 5448 [PubMed: 9605147]

53. Chen $\mathrm{M}$ et al. (2008) Lipid mediators in innate immunity against tuberculosis: opposing roles of PGE2 and LXA4 in the induction of macrophage death. J. Exp. Med 205, 2791 [PubMed: 18955568]

54. Hinchey J et al. (2007) Enhanced priming of adaptive immu nity by a proapoptotic mutant of Mycobacterium tuberculosis. J. Clin. Invest 117, 2279-2288 [PubMed: 17671656]

55. Braverman J et al. (2016) HIF-1a is an essential mediator of IFN- $\gamma$-dependent immunity to Mycobacterium tuberculosis. J. Immunol 197, 1287-1297 [PubMed: 27430718]

56. Wang T et al. (2017) HIFla-induced glycolysis metabolism is essential to the activation of inflammatory macrophages. Mediat. Inflamm 2017, 9029327

57. Wang F et al. (2018) Interferon gamma induces reversible metabolic reprogramming of M1 macrophages to sustain cell viability and pro-inflammatory activity. EBioMedicine 30, 303-316 [PubMed: 29463472]

58. Belaiba RS et al. (2007) Hypoxia up-regulates hypoxia inducible factor-1alpha transcription by involving phos phatidylinositol 3-kinase and nuclear factor kappaB in pulmonary artery smooth muscle cells. Mol. Biol. Cell 18, 4691-4697 [PubMed: 17898080]

59. Walmsley SR et al. (2005) Hypoxia-induced neutrophil survival is mediated by HIF-1alphadependent NF-kappaB activity. J. Exp. Med 201, 105-115 [PubMed: 15630139]

60. Sánchez D et al. (2010) Role of TLR2- and TLR4-mediated signaling in Mycobacterium tuberculosis-induced macrophage death. Cell. Immunol 260, 128-136 [PubMed: 19919859]

61. Fallahi-Sichani M et al. (2012) NF- אB Signaling dynamics play a key role in infection control in tuberculosis. Front. Physiol 3, 170 [PubMed: 22685435]

62. Chan J et al. (1992) Killing of virulent Mycobacterium tuberculosis by reactive nitrogen intermediates produced by activated murine macrophages. J. Exp. Med 175, 1111 [PubMed: 1552282]

63. MacMicking JD et al. (2003) Immune control of tuberculosis by IFN- $\gamma$-inducible LRG-47. Science 302, 654-659 [PubMed: 14576437] 
64. Rich EAT et al. (1997) Mycobacterium tuberculosis (MTB)-stimulated production of nitric oxide by human alveolar macro phages and relationship of nitric oxide production to growth inhibition of MTB. Tuber. Lung Dis 78, 247-255 [PubMed: 10209679]

65. Palmieri EM et al. (2018) Nitric oxide dictates the reprogramming of carbon flux during M1 macrophage polari zation. J. Immunol 200, 170.18

66. Idh J et al. (2012) Resistance to first-line anti-TB drugs is associated with reduced nitric oxide susceptibility in Mycobacterium tuberculosis. PLoS One 7, e39891 [PubMed: 22768155]

67. Baseler WA et al. (2016) Autocrine IL-10 functions as a rheostat for M1 macrophage glycolytic commitment by tuning nitric oxide production. Redox Biol. 10, 12-23 [PubMed: 27676159]

68. Vachharajani VT et al. (2016) Sirtuins link inflammation and metabolism. J Immunol Res 2016, 8167273 [PubMed: 26904696]

69. Cheng CY et al. (2017) Host sirtuin 1 regulates mycobacterial immunopathogenesis and represents a therapeutic target against tuberculosis. Sci. Immunol 2, eaaj1789 [PubMed: 28707004]

70. Yang H et al. (2019) Role of Sirt1 in innate immune mechanisms against Mycobacterium tuberculosis via the inhibition of TAK1 activation. Arch. Biochem. Biophys 667, 49-58 [PubMed: 31029687]

71. Xiao C et al. (2012) Progression of chronic liver inflammation and fibrosis driven by activation of c-JUN signaling in Sirt6 mutant mice. J. Biol. Chem 287, 41903-41913 [PubMed: 23076146]

72. Koivunen $P$ et al. (2007) Inhibition of hypoxia-inducible factor (HIF) hydroxylases by citric acid cycle intermediates: possible links between cell metabolism and stabilization of HIF. J. Biol. Chem 282, 4524-4532 [PubMed: 17182618]

73. Jayaraman $P$ et al. (2013) IL-1 $\beta$ promotes antimicrobial immunity in macrophages by regulating TNFR signaling and caspase-3 activation. J Immunol Res 190, 4196-4204

74. Ogryzko NV et al. (2019) Hif-1a-induced expression of Il-1 $\beta$ protects against mycobacterial infection in zebrafish. J. Immunol 202, 494-502 [PubMed: 30552162]

75. Cardoso MS et al. (2015) Lack of the transcription factor hypoxia-inducible factor 1a (HIF-1a) in macrophages accelerates the necrosis of Mycobacterium avium-induced granulomas. Infect. Immun 83, 3534-3544 [PubMed: 26099585]

76. Voskuil MI et al. (2011) The response of Mycobacterium tuberculosis to reactive oxygen and nitrogen species. Front. Microbiol 2, 105 [PubMed: 21734908]

77. Cai Y et al. (2016) xCT increases tuberculosis susceptibility by regulating antimicrobial function and inflammation. Oncotarget 7, 31001-31013 [PubMed: 27129162]

78. Jha Abhishek K. et al. (2015) Network Integration of parallel metabolic and transcriptional data reveals metabolic modules that regulate macrophage polarization. Immunity 42, 419-430 [PubMed: 25786174]

79. Infantino V et al. (2011) The mitochondrial citrate carrier: a new player in inflammation. Biochem. J 438, 433 [PubMed: 21787310]

80. Infantino V et al. (2014) A key role of the mitochondrial citrate carrier (SLC25A1) in TNFa- and IFN $\gamma$-triggered inflammation. Biochim. Biophys. Acta 1839, 1217-1225 [PubMed: 25072865]

81. Infantino V et al. (2013) ATP-citrate lyase is essential for macrophage inflammatory response. Biochem. Biophys. Res. Commun 440, 105-111 [PubMed: 24051091]

82. Nair S et al. (2018) Irg1 expression in myeloid cells prevents immunopathology during $M$. tuberculosis infection. J. Exp. Med 215, 1035-1045 [PubMed: 29511063]

83. Lampropoulou V et al. (2016) Itaconate links inhibition of succinate dehydrogenase with macrophage metabolic remodeling and regulation of inflammation. Cell Metab. 24, 158-166 [PubMed: 27374498]

84. Pajuelo D et al. (2018) NAD(+) Depletion triggers macrophage necroptosis, a cell death pathway exploited by Mycobacterium tuberculosis. Cell Rep. 24, 429-440 [PubMed: 29996103]

85. Sociali G et al. (2018) SIRT6 deacetylase activity regulates NAMPT activity and NAD(P)(H) pools in cancer cells. FASEB J. 33, 3704-3717 [PubMed: 30514106]

86. Beltrán B et al. (2000) The effect of nitric oxide on cell respiration: A key to understanding its role in cell survival or death. Proc. Natl. Acad. Sci. U. S. A 97, 14602-14607 [PubMed: 11121062] 
87. Everts B et al. (2012) Commitment to glycolysis sustains survival of NO-producing inflammatory dendritic cells. Blood 120, 1422 [PubMed: 22786879]

88. Lerner TR et al. (2017) Mycobacterium tuberculosis replicates within necrotic human macrophages. J. Cell Biol 216, 583-594 [PubMed: 28242744]

89. Menon D et al. (2019) Quantitative lipid droplet proteomics reveals Mycobacterium tuberculosis induced alterations in macrophage response to infection. ACS Infect. Dis 5, 559-569 [PubMed: 30663302]

90. Peyron P et al. (2008) Foamy macrophages from tuberculous patients' granulomas constitute a nutrient-rich reservoir for M. tuberculosis persistence. PLoS Pathog. 4, e1000204 [PubMed: 19002241]

91. Jaisinghani $\mathrm{N}$ et al. (2018) Necrosis driven triglyceride synthe sis primes macrophages for inflammation during Mycobacte rium tuberculosis infection. Front. Immunol 9, 1490-1490 [PubMed: 30018616]

92. Daniel J et al. (2011) Mycobacterium tuberculosis uses host triacylglycerol to accumulate lipid droplets and acquires a dormancy-like phenotype in lipid-loaded macrophages. PLoS Pathog. 7, e1002093 [PubMed: 21731490]

93. Ramakrishnan L (2012) Revisiting the role of the granuloma in tuberculosis. Nat. Rev. Immunol 12, 352 [PubMed: 22517424]

94. Domingo-Gonzalez R et al. (2017) Interleukin-17 limits hypoxia-inducible factor $1 a$ and development of hypoxic gran ulomas during tuberculosis. JCI Insight 2, e92973

95. Guerrini V et al. (2018) Storage lipid studies in tuberculosis reveal that foam cell biogenesis is disease-specific. PLoS Pathog. 14, e1007223 [PubMed: 30161232]

96. Knight M et al. (2018) Lipid droplet formation in Mycobacterium tuberculosis infected macrophages requires IFN- $\gamma / \mathrm{HIF}-1 \mathrm{a}$ signaling and supports host defense. PLoS Pathog. 14, e1006874 [PubMed: 29370315]

97. Siess EA et al. (1982) Role of free oxaloacetate in ketogene sis. Eur. J. Biochem 121, 493-499 [PubMed: 7056252]

98. Rothchild AC et al. (2016) MiR-155-regulated molecular net work orchestrates cell fate in the innate and adaptive immune response to Mycobacterium tuberculosis. Proc. Natl. Acad. Sci. U. S. A 113, E6172 [PubMed: 27681624]

99. Carroll RG et al. (2018) An unexpected link between fatty acid synthase and cholesterol synthesis in proinflammatory macrophage activation. J. Biol. Chem 293, 5509-5521 [PubMed: 29463677]

100. Wilburn KM et al. (2018) Cholesterol and fatty acids grease the wheels of Mycobacterium tuberculosis pathogenesis. Pathogens Dis. 76, fty021

101. Barry CE et al. (1998) Mycolic acids: structure, biosynthesis and physiological functions. Prog. Lipid Res 37, 143-179 [PubMed: 9829124]

102. Kang M-J et al. (1997) A novel arachidonate-preferring acyl-CoA synthetase is present in steroidogenic cells of the rat adrenal, ovary, andtestis. Proc. Natl. Acad. Sci. U. S. A 94, 28802884 [PubMed: 9096315]

103. Duan L et al. (2001) Cytosolic phospholipase A2 participates with TNF-a in the induction of apoptosis of human macro phages infected with Mycobacterium tuberculosis H37Ra. J. Immunol 166, 7469-7476 [PubMed: 11390500]

104. Rocca B and FitzGerald GA (2002) Cyclooxygenases and prostaglandins: shaping up the immune response. Int. Immunopharmacol 2, 603-630 [PubMed: 12013502]

105. Levy BD et al. (2001) Lipid mediator class switching during acute inflammation: signals in resolution. Nat. Immunol 2, 612-619 [PubMed: 11429545]

106. Jia X et al. (2017) The bioinformatics analysis of comparative genomics of Mycobacterium tuberculosis complex (MTBC) provides insight into dissimilarities between intraspecific groups differing in host association, virulence, and epitope diversity. Front. Cell. Infect. Microbiol 7, 88 [PubMed: 28377903]

107. Blischak JD et al. (2015) Mycobacterial infection induces a specific human innate immune response. Sci. Rep 5, 16882 [PubMed: 26586179]

108. Carmona J et al. (2013) Mycobacterium tuberculosis strains are differentially recognized by TLRs with an impact on the immune response. PLoS One 8, e67277 [PubMed: 23840651] 
109. Krishnan N et al. (2011) Mycobacterium tuberculosis lineage influences innate immune response and virulence and is asso ciated with distinct cell envelope lipid profiles. PLoS One 6, e23870 [PubMed: 21931620]

110. Gopal R et al. (2014) Unexpected role for IL-17 in protective immunity against hypervirulent Mycobacterium tuberculosis HN878 infection. PLoS Pathog. 10, e1004099 [PubMed: 24831696]

111. Sinsimer D et al. (2008) The phenolic glycolipid of Mycobacterium tuberculosis differentially modulates the early host cytokine response but does not in itself confer hypervirulence. Infect. Immun 76, 3027-3036 [PubMed: 18443098]

112. Treerat P et al. (2017) Novel role for IL-22 in protection during chronic Mycobacterium tuberculosis HN878 infection. Mucosal Immunol. 10, 1069-1081 [PubMed: 28247861]

113. Lahiri N et al. (2016) Rifampin resistance mutations are asso ciated with broad chemical remodeling of Mycobacterium tuberculosis. J. Biol. Chem 291, 14248-14256 [PubMed: 27226566]

114. Singh A et al. (2015) Comparative proteomic analysis of sequential isolates of Mycobacterium tuberculosis from a patient with pulmonary tuberculosis turning from drug sensitive to multidrug resistant. Indian J. Med. Res 141, 27-45 [PubMed: 25857493]

115. Campodónico VL et al. (2018) Altered Mycobacterium tuberculosis cell wall metabolism and physiology associated with RpoB mutation H526D. Front. Microbiol 9, 494 [PubMed: 29616007]

116. Sun ZR et al. (2014) Preliminary study on the virulence of XDR-TB: Low virulence owing to less cytokine expression through the TLR 2 and TLR4 pathways in BLAB/C mice. Bio-Med. Mater. Eng 24, 3873-3882

117. Basingnaa A et al. (2018) Plasma levels of cytokines (IL-10, IFN- $\gamma$ and TNF-a) in multidrug resistant tuberculosis and drug responsive tuberculosis patients in Ghana. Diseases 7, 2

118. Skolimowska KH et al. (2012) Altered ratio of IFN- $\gamma /$ IL-10 in patients with drug resistant Mycobacterium tuberculosis and HIV-tuberculosis immune reconstitution inflammatory syndrome. PLoS One 7, e46481 [PubMed: 23071578]

119. Jhingan GD et al. (2016) Comparative proteomic analyses of avirulent, virulent, and clinical strains of Mycobacterium tuberculosis identify strain-specific patterns. J. Biol. Chem 291, 14257-14273 [PubMed: 27151218]

120. Nishimura T et al. (2013) The prostaglandin E2 receptor EP4 is integral to a positive feedback loop for prostaglandin E2 production in human macrophages infected with Mycobacterium tuberculosis. FASEB J. 27, 3827-3836 [PubMed: 23759445]

121. Mayer-Barber KD et al. (2014) Host-directed therapy of tuberculosis based on interleukin-1 and type I interferon crosstalk. Nature 511, 99-103 [PubMed: 24990750]

122. Zhang L et al. (2016) Risk factors for pulmonary cavitation in tuberculosis patients from China. Emerg. Microbes Infect 5, e110 [PubMed: 27729644]

123. Wáng YXJ et al. (2018) Radiological signs associated with pulmonary multi-drug resistant tuberculosis: an analysis of published evidences. Quant. Imag. Med. Surg 8, 161-173

124. Dantoft W et al. (2019) Metabolic regulators nampt and Sirt6 serially participate in the macrophage interferon antiviral cascade. Front. Microbiol 10, 355-355 [PubMed: 30886604]

125. Giosuè $S$ et al. (1998) Effects of aerosolized interferon- $a$ in patients with pulmonary tuberculosis. Am. J. Respir. Crit. Care Med 158, 1156-1162 [PubMed: 9769275]

126. Palmero D et al. (1999) Phase II trial of recombinant interferon-b in patients with advanced intractable multidrug-resistant pulmonary tuberculosis: long-term follow-up. Int. J. Tuberc. Lung Dis 3, 214-218 [PubMed: 10094322]

127. Chakraborty P et al. (2013) Drug resistant clinical isolates of Mycobacterium tuberculosis from different genotypes exhibit differential host responses in THP-1 cells. PLoS One 8, e62966 [PubMed: 23667550]

128. Billig S et al. (2017) Lactate oxidation facilitates growth of Mycobacterium tuberculosis in human macrophages. Sci. Rep 7, 6484 [PubMed: 28744015]

129. Nieto RLM et al. (2016) Comparing isogenic strains of Beijing genotype Mycobacterium tuberculosis after acquisition of Isoniazid resistance: A proteomics approach. Proteomics 16, 1376-1380 [PubMed: 26929115] 
130. Tyagi P et al. (2020) Mycobacterium tuberculosis reactivates HIV-1 via exosome-mediated resetting of cellular redox potential and bioenergetics. mBio 11, e03293-19 [PubMed: 32127457]

131. Rinder HT et al. (1998) Significance of ahpC promoter mutations for the prediction of isoniazid resistance in Mycobacterium tuberculosis. Eur. J. Clin. Microbiol. Infect. Dis 17, 508-511 [PubMed: 9764555]

132. Sherman DR et al. (1996) Compensatory ahpC gene expres sion in isoniazid-resistant Mycobacterium tuberculosis. Science 272, 1641 [PubMed: 8658136]

133. Cho HJ et al. (2020) Different macrophage polarization be tween drug-susceptible and multidrugresistant pulmonary tu berculosis. BMC Infect. Dis 20, 81 [PubMed: 31996142]

134. Lee W et al. (2013) Intracellular Mycobacterium tuberculosis exploits host-derived fatty acids to limit metabolic stress. J. Biol. Chem 288, 6788-6800 [PubMed: 23306194]

135. Bisson GP et al. (2012) Upregulation of the phthiocerol dimycocerosate biosynthetic pathway by rifampin-resistant, rpoB mutant Mycobacterium tuberculosis. J. Bacteriol 194, 6441-6452 [PubMed: 23002228]

136. Nieto RLM et al. (2018) Biochemical characterization of isoniazid-resistant Mycobacterium tuberculosis: can the analy sis of clonal strains reveal novel targetable pathways? Mol. Cell. Proteom 17, 1685

137. Pal R et al. (2017) Comparative lipidomics of drug sensitive and resistant Mycobacterium tuberculosis reveals altered lipid imprints. 3 Biotech 7-325

138. Nieto R et al. (2016) Virulence of Mycobacterium tuberculosis after acquisition of isoniazid resistance: individual nature of katG mutants and the possible role of AhpC. PLoS One 11, e0166807 [PubMed: 27893795]

139. Di Paolo NC et al. (2015) Interdependence between Interleukin-1 and tumor necrosis factor regulates TNF-dependent control of Mycobacterium tuberculosis infection. Immunity 43, 11251136 [PubMed: 26682985]

140. Kviatcovsky D et al. (2017) Mycobacterium tuberculosis multidrug-resistant strain M induces low IL-8 and inhibits TNF-a secretion by bronchial epithelial cells altering neutrophil effector functions. Mediat. Inflamm 2017, 13

141. Sharma M et al. (2012) Intracellular survival of Mycobacterium tuberculosis in macrophages is modulated by phenotype of the pathogen and immune status of the host. Int. J. Mycobacteriol 1, 65-74 [PubMed: 26787058]

142. Fisher-Hoch SP et al. (2008) Type 2 diabetes and multidrug-resistant tuberculosis. Scand. J. Infect. Dis 40, 888-893 [PubMed: 18728934]

143. Liu Q et al. (2017) Diabetes mellitus and the risk of multidrug resistant tuberculosis: a metaanalysis. Sci. Rep 7, 1090 [PubMed: 28439071]

144. Salindri AD et al. (2016) Diabetes reduces the rate of spu tum culture conversion in patients with newly diagnosed multidrug-resistant tuberculosis. Open Forum Infect. Dis 3, ofw126 [PubMed: 27419188]

145. Kang YA et al. (2013) Impact of diabetes on treatment out comes and long-term survival in multidrug-resistant tuberculosis. Respiration 86, 472-478 [PubMed: 23689646]

146. Lopez-Lopez $\mathrm{N}$ et al. (2018) Type-2 diabetes alters the basal phenotype of human macrophages and diminishes their capacity to respond, internalise, and control Mycobacterium tuberculosis. Mem. Inst. Oswaldo Cruz 113, e170326 [PubMed: 29513874]

147. Yew WW et al. (2017) Oxidative stress and TB outcomes in patients with diabetes mellitus? J. Antimicrob. Chemother 72, 1552-1555 [PubMed: 28204508]

148. Singhal A et al. (2014) Metformin as adjunct antituberculosis therapy. Sci. Trans. Med 6, 263ra159

149. Lee Y-J et al. (2018) The effect of metformin on culture con version in tuberculosis patients with diabetes mellitus. Korean J. Intern. Med 33, 933-940 [PubMed: 29540054] 


\section{Highlights}

$M t b$ infection drives metabolic reprogramming for induction of protective immune responses.

Drug resistance in $M t b$ is associated with changes in lipid and protein expression that can mediate differential host-pathogen interactions.

Rifampicin-resistant $M t b$ strains carrying the $\mathrm{H} 445 \mathrm{Y}$ mutation modulate host metabolic reprogramming and alter downstream immune responses. 


\section{Outstanding Questions}

What drug-resistance mutations are associated with altered immunometabolism?

What is the effect of multiple drug-resistance mutations on modulating host metabolism and downstream immune responses?

Mycobacterial metabolism is linked to host cellular metabolism. Mtb is able to metabolize various host metabolites (including lactate, pyruvate, and cholesterol) as a nutrient source. Given the strong evidence that drug-resistance mutations impact cell-wall biosynthesis, the nutrient requirements for drug-resistant $M t b$ may differ from those of drug-susceptible $M t b$. What is the relationship between drug-resistant $M t b$ and host cellular metabolism?

What impact does drug resistance in $M t b$ have on disease outcome in patients? 


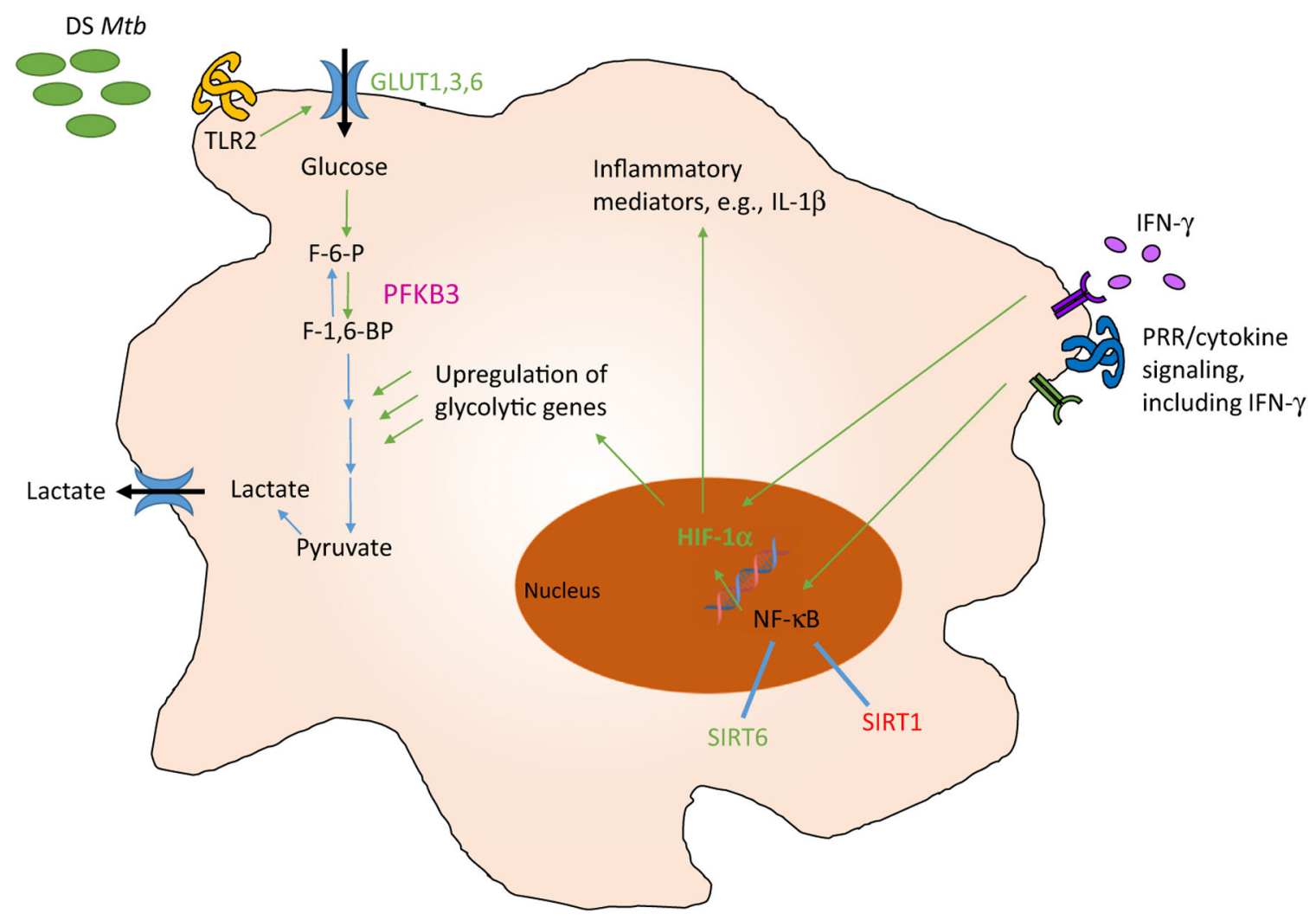

Figure 1. Drug-Susceptible (DS) Mycobacterium tuberculosis (Mtb) Infection Drives Increased Glycolysis.

DS $M t b$ infection drives the Warburg effect: increased glycolytic flux driving production of lactate and decreased mitochondrial oxidative metabolism. Following Toll-like receptor (TLR)2 stimulation, increased glycolysis is mediated by upregulation of key genes, including those encoding glucose transporters GLUT1/3/6, although certain genes, like $P f k b 3$, are differentially regulated by $M t b$ strains of different lineages. Activation of various pattern-recognition receptors (PRRs) and cytokine receptors drives the induction of the nuclear factor kappa B (NF- $\kappa \mathrm{B})$ pathway, which drives hypoxia inducible factor (HIF-1a) expression, leading to further upregulation of glycolytic genes and the production of critical inflammatory mediators like interleukin (IL)-1 $\beta$. Sirtuins SIRT1 and SIRT6 downregulate $\mathrm{NF}-\kappa \mathrm{B}$ and are differentially regulated by $M t b$ infection. Green indicates upregulation, red indicates downregulation, and purple indicates differential expression that varies between Mtb strains. Abbreviations: IFN, interferon. 


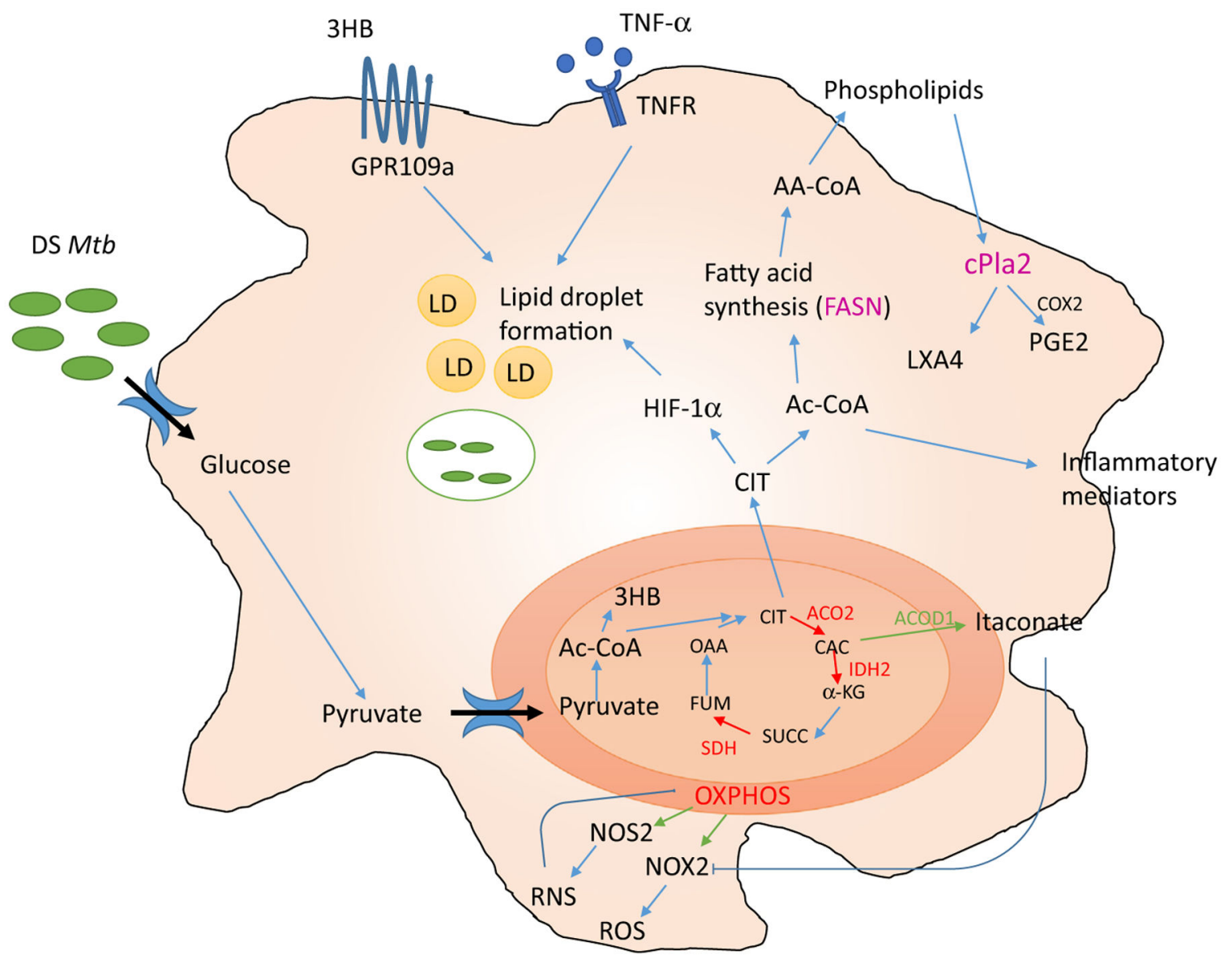

Figure 2. Drug-Susceptible (DS) Mycobacterium tuberculosis (Mtb) Infection Modulates the tricarboxylic acid (TCA) Cycle, Oxidative Phosphorylation (OXPHOS), and Fatty Acid (FA) Metabolism.

While glycolysis is upregulated, the TCA cycle and OXPHOS are downregulated in the acute phase of $M t b$ infection. Various TCA cycle enzymes are downregulated, including ACO2, isocitrate dehydrogenase 2 (IDH2), and succinate dehydrogenase (SDH), to drive reduced oxidative metabolism. Accumulation of TCA cycle intermediates like citrate and succinate increase the expression and stability of hypoxia inducible factor (HIF)-1a and drives production of the metabolite itaconate. Decreased OXPHOS also drives increased reactive oxygen species (ROS) and reactive nitrogen species (RNS). Acetyl coenzyme-A (Ac-CoA) generated in the mitochondria is converted into the ketone body $3 \mathrm{HB}$ rather than fed into the TCA cycle. 3HB signals through GPR109a to drive formation of lipid bodies. Citrate export and the stabilization of HIF-1a may also drive increased lipid droplet (LD) formation. Citrate conversion to Ac-CoA in the cytoplasm feeds into FA metabolism, which is differentially regulated by DS $M t b$ strains of different lineages. Green indicates upregulation, red indicates downregulation, and purple indicates differential expression that varies between $M t b$ strains. Abbreviations: AA-CoA, CAC, CIT, FUM, fumarate; $a-K G$, LXA4, lipoxin A4; NOS2, nitric oxide synthase 2; NOX2, OAA, oxaloacetate; PGE2, prostaglandin E2; SUCC,TNF, tumor necrosis factor; TNFR, tumor necrosis factor receptor. 


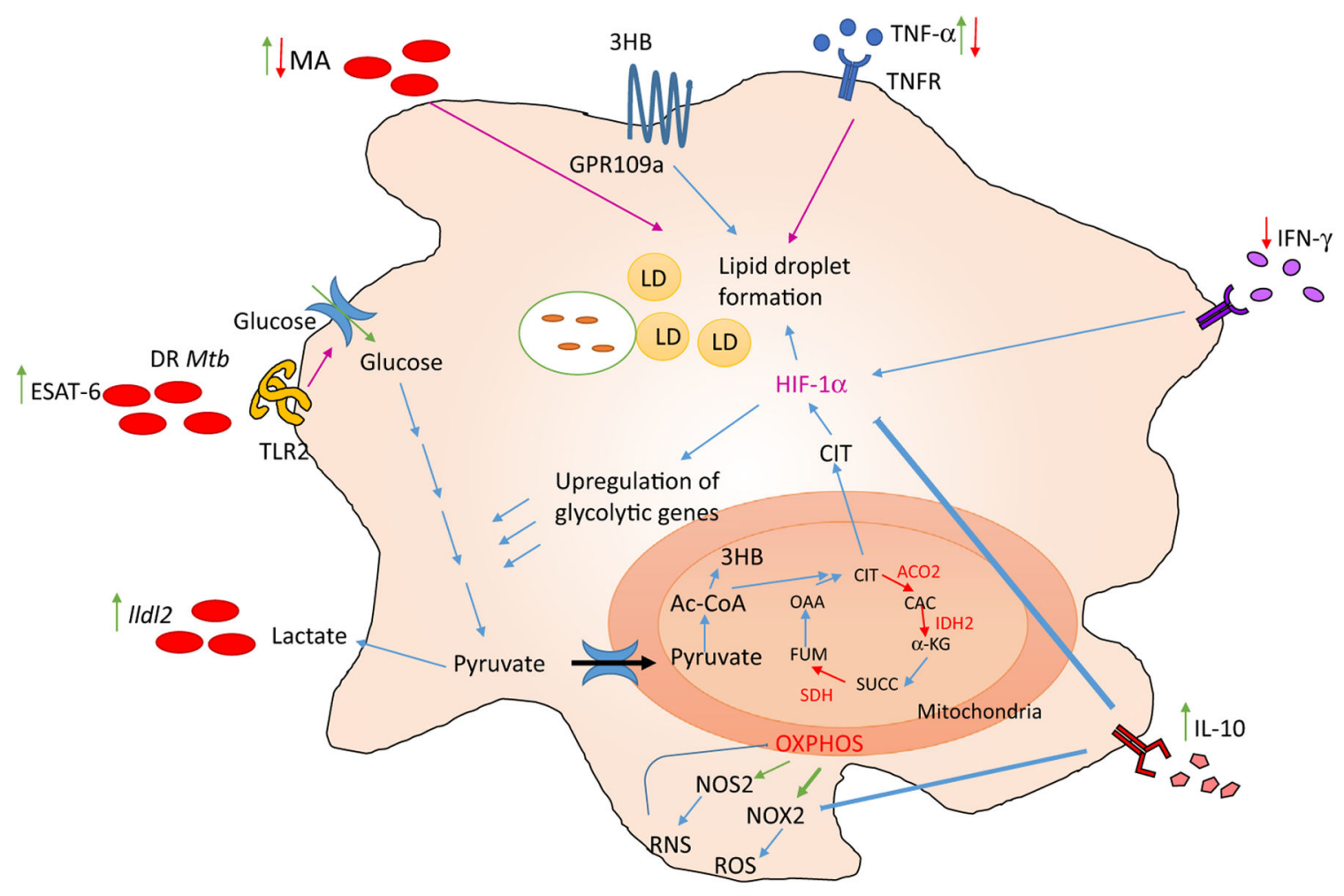

Figure 3. Drug-Resistant (DR) Mycobacterium tuberculosis (Mtb) Infection Modulates Metabolic Reprogramming.

DR $M t b$ strains have altered cell wall lipid expression and drive differential immune responses during infection in comparison with drug susceptible (DS) strains. Reduced Tolllike receptor (TLR)2 stimulation by some DR $M t b$ strains may impair optimal glycolytic flux, although upregulation of ESAT-6 expression by DR $M t b$ strains may enhance it. Lactate is secreted from the cell as a by-product of aerobic glycolysis; some DR Mtb strains have increased expression of the $11 d 12$ gene that encodes an enzyme that allows $M t b$ to metabolize lactate as a nutrient source. The increased ratio of interleukin (IL)-10:interferon (IFN)- $\gamma$ in multidrug-resistant (MDR) tuberculosis (TB) patients may suggest that hypoxia inducible factor (HIF)-1a expression is not strongly upregulated, which correlates with lower IL-1 $\beta$ production during DR $M t b$ infection. Critical tricarboxylic acid (TCA) cycle enzymes are downregulated by DR $M t b$ infection, leading to the accumulation of metabolic intermediates and maintaining production of reactive nitrogen species (RNS) and reactive oxygen species (ROS). However, increased induction of immunoregulatory molecules like IL-10 may interfere with RNS/ROS generation and downstream protective inflammatory responses. Lipid droplet (LD) formation may be modulated by altered mycolic acid (MA) expression in the cell wall of DR $M t b$, and/or differential induction of tumor necrosis factor (TNF)-a may additionally drive lipid body formation. Green indicates upregulation, red indicates downregulation, and purple indicates differential expression that varies between DR $M t b$ isolates. Abbreviations: CAC, CIT, FUM, fumarate; IDH2, isocitrate dehydrogenase 2; a-KG, NOS2, nitric oxide synthase 2; NOX2, OAA, oxaloacetate; 
OXPHOS, oxidative phosphorylation; SDH, succinate dehydrogenase; SUCC, TNFR, tumor necrosis factor receptor. 
Table 1.

Host Gene Products Related to Immunometabolism ${ }^{a}$

\begin{tabular}{|c|c|c|c|c|c|}
\hline Pathway & Host gene/protein & Abbreviation & Function & Response to DS Mtb & $\begin{array}{l}\text { Response to DR } M t b \\
\text { (known or proposed) }\end{array}$ \\
\hline \multirow[t]{7}{*}{ Glycolysis } & $\begin{array}{l}\text { 6-Phosphofructo-2-Kinase/ } \\
\text { Fructose-2,6-Biphosphatase } \\
3\end{array}$ & Pfkfb3 & $\begin{array}{l}\text { Synthesis and } \\
\text { degradation of fructose- } \\
\text { 2,6-bisphosphate } \\
\text { during glucose } \\
\text { metabolism }\end{array}$ & $\begin{array}{l}\text { Upregulated to varying } \\
\text { extent by DS } M t b \\
\text { strains; } M t b \text { CDC } 1551 \\
\text { drives higher } \\
\text { expression than } M t b \\
\text { HN878 [36] }\end{array}$ & $\begin{array}{l}\text { Weakly upregulated by } \\
\text { certain MDR } M t b \text {; } \\
\text { MDR } M t b \text { W_7642 } \\
\text { drives lower } \\
\text { expression than } M t b \\
\text { HN878 [18] }\end{array}$ \\
\hline & Glucosetransporter 1 & Glut1 & $\begin{array}{l}\text { Transport ofglucose } \\
\text { into the cell }\end{array}$ & $\begin{array}{l}\text { Upregulated by DS } \\
\text { Mtb in human } \\
\text { macrophages [40] }\end{array}$ & $\begin{array}{l}\text { No direct evidence of } \\
\text { changes in }\end{array}$ \\
\hline & Glucose transporter 3 & Glut3 & $\begin{array}{l}\text { Transport ofglucose } \\
\text { into the cell }\end{array}$ & $\begin{array}{l}\text { Upregulated by DS } \\
\text { Mtb in human } \\
\text { macrophages [40] }\end{array}$ & $\begin{array}{l}\text { expression compared } \\
\text { to DS } M t b \text {; increased } \\
\text { ESAT- } 6 \text { expression } \\
\text { may suggest increased } \\
\text { glucose uptake }\end{array}$ \\
\hline & Glucose transporter 6 & Glut6 & $\begin{array}{l}\text { Transport of glucose } \\
\text { into the cell }\end{array}$ & $\begin{array}{l}\text { Upregulated by DS } \\
\text { Mtb in murine } \\
\text { BMDMs [39] }\end{array}$ & \\
\hline & $\begin{array}{l}\text { Hypoxia Inducible factor } 1 \\
\text { subunit alpha }\end{array}$ & $\mathrm{HIF}-1 a$ & $\begin{array}{l}\text { Transcriptional } \\
\text { regulator of metabolism } \\
\text { and the response to } \\
\text { hypoxia }\end{array}$ & $\begin{array}{l}\text { Upregulated by DS } \\
\text { Mtb infection to } \\
\text { mediate shift to aerobic } \\
\text { glyolysis }[25,29,32,55]\end{array}$ & $\begin{array}{l}\text { No direct evidence of } \\
\text { changes in expression } \\
\text { compared to DS } M t b \text {; } \\
\text { impaired IFN- } \gamma \\
\text { response may prevent } \\
\text { sustained HIF-1 a } \\
\text { expression }[117,118]\end{array}$ \\
\hline & $\begin{array}{l}\text { Hypoxia Inducible factor } \\
\text { prolyl- hydroxylases }\end{array}$ & PHD1 -3 & $\begin{array}{l}\text { Hydroxylate HIF-1 a to } \\
\text { target it for degradation }\end{array}$ & Inhibited $[25,29,32,55]$ & Unknown \\
\hline & $\begin{array}{l}\text { Peroxisome proliferator- } \\
\text { activated receptor gamma } \\
\text { coactivator 1-beta }\end{array}$ & $\mathrm{Pgclb}$ & $\begin{array}{l}\text { Stimulates several } \\
\text { transcription factors; it } \\
\text { is involved in glucose } \\
\text { metabolism }\end{array}$ & $\begin{array}{l}\text { Upregulated during } \\
\text { later stages of infection } \\
{[36]}\end{array}$ & Unknown \\
\hline \multirow[t]{5}{*}{$\begin{array}{l}\text { Cytokines } \\
\text { and their } \\
\text { receptors }\end{array}$} & Interleukin 10 & IL-10 & $\begin{array}{l}\text { Immuno-regulatory } \\
\text { cytokine that limits } \\
\text { immune responses to } \\
\text { prevent damage to the } \\
\text { host and maintain tissue } \\
\text { homeostasis }\end{array}$ & $\begin{array}{l}\text { Induced by DS } M t b \\
\text { infection to assist in } \\
\text { immune evasion }\end{array}$ & $\begin{array}{l}\text { MDR TB patients have } \\
\text { elevated IL-10 in } \\
\text { plasma [116,117]; } \\
\text { increased type I IFN } \\
\text { may also drive more } \\
\text { IL-10 [18] }\end{array}$ \\
\hline & Interleukin 1 beta & $\mathrm{IL}-1 \beta$ & $\begin{array}{l}\text { Proinflammatory } \\
\text { cytokine }\end{array}$ & $\begin{array}{l}\text { Expression is induced } \\
\text { by DS Mtb }\end{array}$ & $\begin{array}{l}\text { Variable induction in } \\
\text { comparison with } \\
\text { H37Rv by different } \\
\text { MDR strains [118]; } \\
\text { may have lower } \\
\text { induction due to } \\
\text { certain DR mutations } \\
\text { [18] }\end{array}$ \\
\hline & Tumor necrosis factor alpha & TNF- $a$ & $\begin{array}{l}\text { Proinflammatory } \\
\text { cytokine }\end{array}$ & $\begin{array}{l}\text { Expression is induced } \\
\text { by DS } M t b\end{array}$ & $\begin{array}{l}\text { Lower [140] or higher } \\
\text { [117] expression in the } \\
\text { serum of DR TB } \\
\text { patients in comparison } \\
\text { with DS TB patients, } \\
\text { depending on study } \\
\text { population }\end{array}$ \\
\hline & Interferon gamma & IFN- $\gamma$ & $\begin{array}{l}\text { Proinflammatory } \\
\text { cytokine }\end{array}$ & $\begin{array}{l}\text { Expression is induced } \\
\text { by DS } M t b\end{array}$ & $\begin{array}{l}\text { Lower levels of IFN- } \\
\text { rin the serum of MDR } \\
\text { TB patients in } \\
\text { comparison with DS } \\
\text { TB }[117,118]\end{array}$ \\
\hline & $\begin{array}{l}\text { Tumor necrosis factor } \\
\text { receptor }\end{array}$ & TNFR & Receptor for $\mathrm{TNFa}$ & $\begin{array}{l}\text { Upregulated by DS } \\
\text { Mtb [139] }\end{array}$ & Unknown \\
\hline
\end{tabular}




\begin{tabular}{|c|c|c|c|c|c|}
\hline Pathway & Host gene/protein & Abbreviation & Function & Response to DS $M t b$ & $\begin{array}{l}\text { Response to DR } M t b \\
\text { (known or proposed) }\end{array}$ \\
\hline \multirow[t]{3}{*}{$\begin{array}{l}\text { Switch to } \\
\text { aerobic } \\
\text { glycolysis }\end{array}$} & Toll-like receptor 2 & TLR2 & $\begin{array}{l}\text { Drives } \\
\text { proinflammatory } \\
\text { cytokine production, } \\
\text { expression of co- } \\
\text { stimulatory molecules, } \\
\text { and activation of } \\
\text { antigen presenting } \\
\text { cells; important for } \\
\text { initiating shift of } \\
\text { cellular metabolism to } \\
\text { aerobic glycolysis }\end{array}$ & $\begin{array}{l}\text { Can be stimulated by } \\
\text { various } M t b \text { bacterial } \\
\text { products, potentially } \\
\text { including ESAT-6 [42- } \\
45]\end{array}$ & $\begin{array}{l}\text { Some XDR Mtb } \\
\text { strains may induce less } \\
\text { TLR2 stimulation } \\
\text { [116]; some MDR } M t b \\
\text { strains have increased } \\
\text { expression of ESAT-6 } \\
\text { that may drive more } \\
\text { TLR2 stimulation } \\
\text { [119] }\end{array}$ \\
\hline & Protein kinase B & PLB/Akt & $\begin{array}{l}\text { Key component of the } \\
\text { Akt signaling pathway } \\
\text { that promotes cell } \\
\text { metabolism, growth, } \\
\text { proliferation, and } \\
\text { survival }\end{array}$ & $\begin{array}{l}\text { Activated by DS Mtb } \\
\text { to drive metabolic } \\
\text { reprogramming to } \\
\text { aerobic glycolysis[32] }\end{array}$ & $\begin{array}{l}\text { Differential activation } \\
\text { by DR } M t b \text { of these } \\
\text { particular genes is } \\
\text { unclear; impaired } \\
\text { aerobic glycolysis } \\
\text { induction by certain }\end{array}$ \\
\hline & $\begin{array}{l}\text { Mammalian target of } \\
\text { rapamycin }\end{array}$ & mTOR & $\begin{array}{l}\text { Central regulator of cell } \\
\text { growth }\end{array}$ & & DR MItb strains [18] \\
\hline \multirow[t]{3}{*}{$\begin{array}{l}\text { Sirtuins } \\
\text { and related } \\
\text { proteins }\end{array}$} & Sirtuin 1 & SIRT1 & $\begin{array}{l}\text { NAD-dependent } \\
\text { deacetylase that } \\
\text { impacts a variety of } \\
\text { cellular functions, } \\
\text { including energy } \\
\text { metabolism, cell } \\
\text { survival and stress } \\
\text { responses }\end{array}$ & $\begin{array}{l}\text { Downregulated by DS } \\
\text { Mtb [68]; increased } \\
\text { expression may aid } \\
\text { Mtb control but } \\
\text { exacerbate } \\
\text { immunopathology } \\
{[69,70]}\end{array}$ & Unknown \\
\hline & Sirtuin 6 & SIRT6 & $\begin{array}{l}\text { NAD-dependent } \\
\text { deacetylase that } \\
\text { impacts a variety of } \\
\text { cellular functions, } \\
\text { including energy } \\
\text { metabolism, cell } \\
\text { survival and stress } \\
\text { responses }\end{array}$ & $\begin{array}{l}\text { Upregulated by DS } \\
\text { Mtb [36] }\end{array}$ & \\
\hline & $\begin{array}{l}\text { Nicotinamide } \\
\text { phosphoribosyltransferase }\end{array}$ & Nampt & $\begin{array}{l}\text { Regulator of the } \\
\text { intracellular NAD pool }\end{array}$ & $\begin{array}{l}\text { Upregulated by DS } \\
\text { Mtb [36] }\end{array}$ & \\
\hline \multirow[t]{4}{*}{ TCA cycle } & Aconitase 2 & $\mathrm{ACO} 2$ & $\begin{array}{l}\text { Part of the TCA cycle } \\
\text { where it converts citrate } \\
\text { into isocitrate }\end{array}$ & & \\
\hline & isocitrate dehydrogenase 2 & IDH2 & $\begin{array}{l}\text { Part of the TCA cycle } \\
\text { where it converts } \\
\text { isocitrate into alpha- } \\
\text { ketoglutarate }\end{array}$ & & $\begin{array}{l}\text { No direct evidence of } \\
\text { changes in expression } \\
\text { compared with DS } \\
\text { Mtb; }\end{array}$ \\
\hline & $\begin{array}{l}\text { Pyruvate dehydrogenase } \\
\text { complex }\end{array}$ & PDC & $\begin{array}{l}\text { Complex of three } \\
\text { enzymes that acts as } \\
\text { part of the TCA cycle } \\
\text { to convert pyruvate into } \\
\text { acetyl-CoA }\end{array}$ & & $\begin{array}{l}\text { however, there is } \\
\text { evidence for } \\
\text { downregulation of } \\
\text { OXPHOS }[18,131]\end{array}$ \\
\hline & Succinate dehydrogenase & SDH & $\begin{array}{l}\text { Part of the TCA cycle } \\
\text { where it converts } \\
\text { succinate to fumarate }\end{array}$ & & \\
\hline \multirow[t]{2}{*}{$\begin{array}{l}\text { Proteins } \\
\text { related }\end{array}$} & Nitric oxide synthase 2 & Nos2 & Production of NO & $\begin{array}{l}\text { Expression is induced } \\
\text { by DS Mtb }\end{array}$ & Unknown \\
\hline & $\begin{array}{l}\text { Solute carrier family } 7 \\
\text { member } 11\end{array}$ & $\begin{array}{l}\mathrm{xCT} \\
\text { (SLC7A11) }\end{array}$ & $\begin{array}{l}\text { Antiporter that imports } \\
\text { cysteine and exports } \\
\text { glutamate }\end{array}$ & $\begin{array}{l}\text { Increased expression } \\
\text { [76] }\end{array}$ & \\
\hline
\end{tabular}

${ }^{a}$ The known function(s) of critical host genes and proteins related to immunometabolism are annotated. If known, the impact of drug-susceptible (DS) or drug-resistant (DR) Mtb infection on the function or expression of these genes/proteins is included. 
Table 2.

Mycobacterial Gene Products Related to Immunometabolism ${ }^{a}$

\begin{tabular}{|c|c|c|c|c|}
\hline Pathway & Mtb gene/protein & Abbreviation & Function & Expression in DR Mtb strains \\
\hline \multirow[t]{2}{*}{$\begin{array}{l}\text { Secreted } \\
\text { proteins }\end{array}$} & $\begin{array}{l}6 \mathrm{kDa} \text { early secretory } \\
\text { antigenic target }\end{array}$ & ESAT-6 & Abundantly secreted virulence factor & $\begin{array}{l}\text { Upregulated by some MDR } M t b \\
\text { isolates [119] }\end{array}$ \\
\hline & $\begin{array}{l}\text { Tuberculosis necrotizing } \\
\text { toxin }\end{array}$ & TNT & $\begin{array}{l}\text { NAD+ glycohydrolase which induces } \\
\text { necrosis by known mechanism }\end{array}$ & $\begin{array}{l}\text { Unknown if expression differs } \\
\text { from DS } M t b\end{array}$ \\
\hline \multirow[t]{3}{*}{$\begin{array}{l}\text { Involved in drug } \\
\text { resistance }\end{array}$} & $\begin{array}{l}\text { Beta subunit of RNA } \\
\text { polymerase }\end{array}$ & rpoB & $\begin{array}{l}\text { Subunit of RNA polymerase, which } \\
\text { catalyzes transcription of RNA from } \\
\text { DNA }\end{array}$ & $\begin{array}{l}\text { Rifampicin-resistant } M t b \text { strains } \\
\text { frequently carry mutations in the } \\
\text { 81-bp 'rifampicin resistance } \\
\text { determining region' of rpoB }\end{array}$ \\
\hline & Catalase peroxidase & katG & $\begin{array}{l}\text { Enzyme with broad catalase and } \\
\text { peroxidase activity; processes INH to } \\
\text { its active form }\end{array}$ & $\begin{array}{l}\text { Mutations within katG can give } \\
\text { rise to INH resistance }\end{array}$ \\
\hline & $\begin{array}{l}\text { Alkyl hydroperoxide } \\
\text { reductase C }\end{array}$ & ahpC & Peroxidase & $\begin{array}{l}\text { Upregulated in INH-resistant } \\
\text { mutants [131] }\end{array}$ \\
\hline $\begin{array}{l}\text { Bacterial } \\
\text { metabolism }\end{array}$ & $\begin{array}{l}\text { L-lactate dehydrogenase } \\
\text { (cytochrome) }\end{array}$ & $11 \mathrm{dd} 2$ & Conversion of lactate to pyruvate & $\begin{array}{l}\text { Upregulated in INH-resistant } \\
\text { mutants [129] }\end{array}$ \\
\hline \multirow[t]{5}{*}{$\begin{array}{l}\text { Cell wall } \\
\text { associated }\end{array}$} & $\begin{array}{l}\text { Phthiocerol } \\
\text { dimycocerosates }\end{array}$ & PDIM & \multirow{4}{*}{$\begin{array}{l}\text { Various proposed roles related to } \\
\text { virulence and immune responses; the } \\
\text { toxic intermediate propionyl-coa can } \\
\text { also be incorporated into these } \\
\text { multimethyl branched FAs }\end{array}$} & \multirow[t]{4}{*}{$\begin{array}{l}\text { May be upregulated in some DR } \\
\text { Mtb strains }[18,113,135]\end{array}$} \\
\hline & Sulfolipid-1 & SL-1 & & \\
\hline & Polyacyltrehalose & PAT & & \\
\hline & Lipooligosaccharide & LOS & & \\
\hline & Mycolic acid & MA & $\begin{array}{l}\text { Major component of the } M t b \text { cell wall; } \\
\text { may also drive foam cell formation }\end{array}$ & $\begin{array}{l}\text { Variable amounts of MAs have } \\
\text { been found in DR strains in } \\
\text { comparison with DS Mtb, } \\
\text { perhaps due to differences in } \\
\text { which DR mutations are carried } \\
{[137,138]}\end{array}$ \\
\hline
\end{tabular}

${ }^{a}$ The known function(s) of $M t b$ genes and proteins are annotated as they relate to immunometabolism, as is any differential expression associated with drug resistance. 